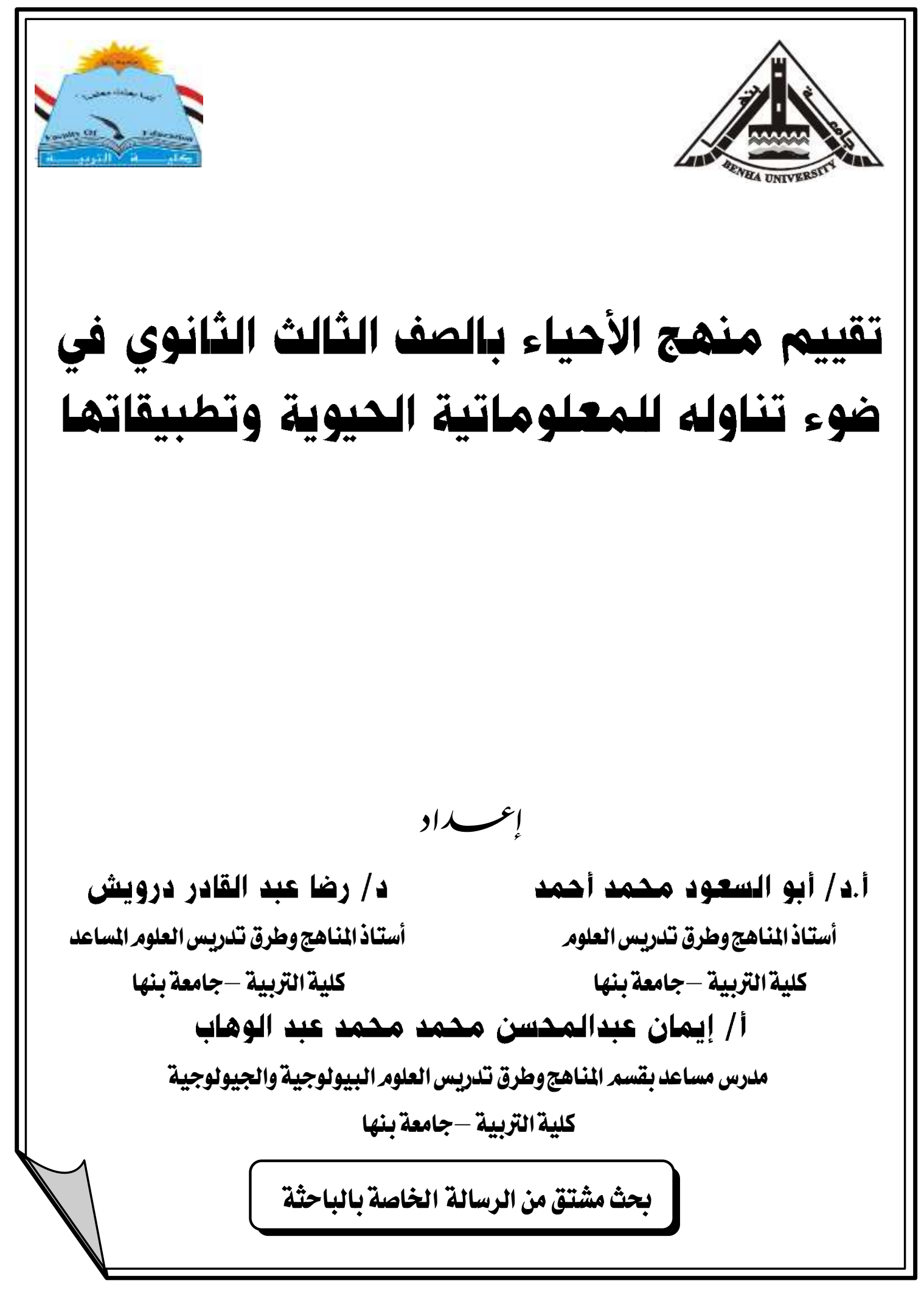




\section{تقييم منهج الأحياء بالصف الثالث الثانوي \\ في ضوء تناوله للمعلوماتية الحيوية وتطبيقاتها}

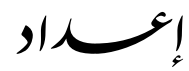

دا دضا عبد القالدر درويش

أستاذ المناهج وطرق تلدريس العلوم المساعد

كلية التربية - جامعة بنها
أ.د/ أبو السعود محمد أحمد

أستاذ المناهج وطرق تلريس العلوم

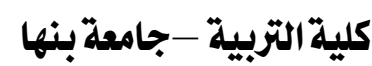

أ / إيمان عبدالمدسن مهمد مهمد وبد الوهاب

ملدرس مساعد بقسم المناهج وطرق تلدريس العلوم البيولوجية والجيولوجية

كلية التربية -جامعة بنها

المستخلــ

يهدف البحث الحالى إلى تطوير منهج الأحياء بالصف الثالث بالمرحلة الثانوية في ضوء المعلوماتية الحيوية ولتحقيق ذلك تم إعداد استطلاع رأي بمجالات المعلوماتية الحيوية وتطبيقاتها التي ينبغي تناولها في منهج الأحياء بالصف الثالث الثانوي، إعداد قائمتين بالمعايير التي ينبغي مراعاتها في أهداف ومحتوى منهج الأحياء بالصف الثالث الثانوي في ضوه قائمة مجالات المعلوماتية الحيوية وتطبيقاتها وضبطهما من خلال عرضهما على السادة المحكمين وتعديلهما في ضوء آرائهم، تحليل أهداف ومحتوى منهج الأحياء بالصف الثالث الثانوي وتقييمها في ضوء قائمتي المعايير (الأهداف والمحتوى، وأوضحت نتائج البحث:

تدني مستوى تناول أهداف منهج الأحياء بالصف الثالث بالمرحلة الثانوية لمعايير ومؤشرات

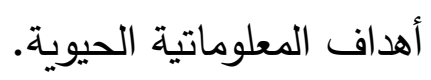

تدني مستوى تناول محتوى منهج الأحياء بالصف الثالث بالمرحلة الثانويـة لمعايير

$$
\text { ومؤشرات محتوى المعلوماتية الحيوية. }
$$




\section{المقـدمسة والإحسـاس بالمشكلـئة:}

يعد تدريس المعلوماتية الحيوية من أحدث التوجهات في التربية المعاصرة في القرن

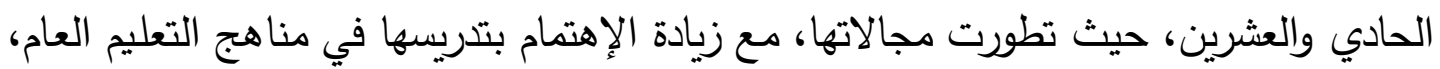

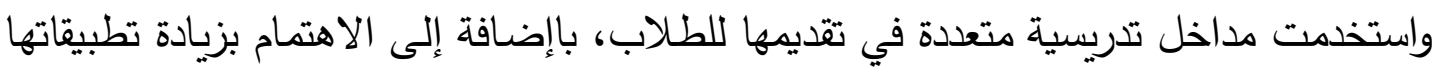
العملية، وتقديم التضمينات الإجتماعية والأخلاقية المرتبطة بها. (Indra, 2010, 535) وتتحدد أهداف المعلوماتية الحيوية فيما يأتي: Rao, Das, Rao \& Srinubabum) (Fulekar, 2009 , 208)، 2008, 501)

تنظيم المعلومات في قواعد البيانات بطريقة تمكن الباحثين من الوصول إليها بسهولة. تطوير أدوات حاسوبية تساعد في تحليل وإدارة فعالة للأنماط المختلفة من البيانات. هاستخدام الأدوات الحاسوبية لتحليل البيانات، وتفسير النتائج بطريقة ذات مغزى من

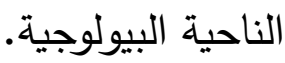

ومن مظاهر الاهتمام بالمعلوماتية الحيوية: عقد العديد من المؤتمرات، ومنها: The EighthAsia المؤتمر الثامن للمعلوماتية الحيوية في آسيا والهحيط الهادئ Pacific Bioinformatics Conference, Bangalore, India

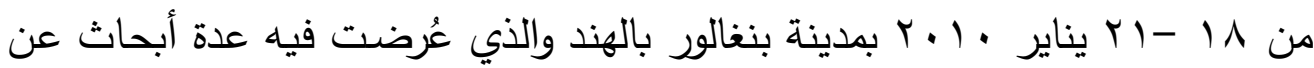
تطبيقات المعلوماتية الحيوية.

The Tenth Asia المؤتمر العاشر للمعلوماتية الحيوية في آسيا والهحيط الهادي Pacific Bioinformatics Conference Melbourne, Australia

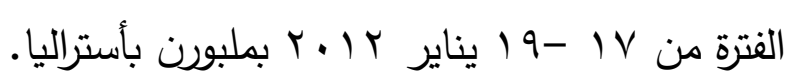

المؤتمر الدولي حول المعلوماتية الحيوية والطب الحيوي The IEEE International Conference on Bioinformatics and Biomedicine

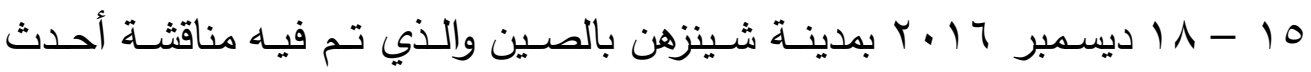
الأبحاث في المعلوماتية الحيوية والمعلوماتية الصحية. 
9th International Conference المؤتمر الدولي التاسع حول المعلوماتية الحيوية on Bioinformatics Paris, France

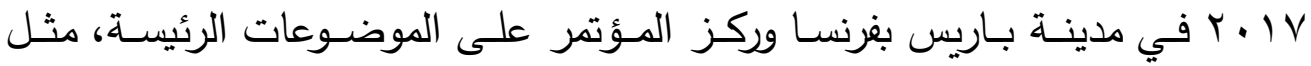

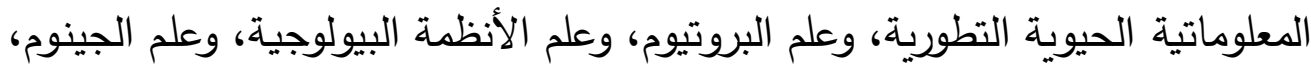

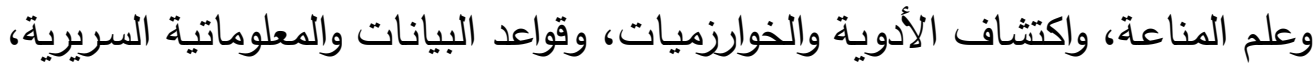
والإحصاء الحيوي والمعلوماتية الحيوية، والتقارير السريرية.

9th المؤتمر الـدولي التاسـع لنمـاذج وطـرق وخوارزميـات المعلوماتيـة الحيويـة International Conference on Bioinformatics Models, Methods and Algorithms Funchal, Madeira, Portugal

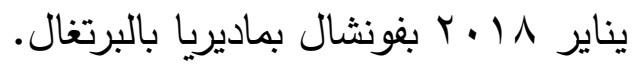

كما أجريت عدة دراسـات اهتمت بالمعلوماتيـة الحيويـة ومنها ما اهتم بإعداد برنامج مقترح أو وحدة مقترحة في المعلوماتية الحيوية والتحقق من فاعليتها كما في دراسات هوارد

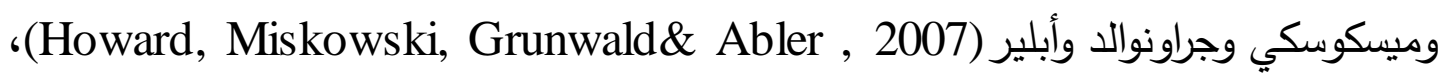

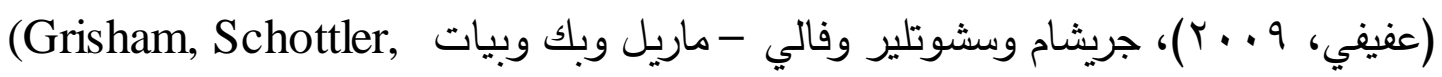
(Marques et al. , 2014) ، ماركس وآخرون Valli-Marill, Beck \& Beatt, 2010) (أبو زيد، 0 ( • (Y)، وماشلوف وجيلبرت وبين - دور وياردن - Machluf, Gelbart, Ben) . Dor \& Yarden, 2016) وهنالك العديد من الدراسات التي اهتمت بتدريس المعلوماتية الحيوية باستخدام مداخل تدريسية وإثراء بيئة التعلم، مثل دراسات: بيدنارسكي وإيلجن وباكراسي \& (Bednarski, Elgin ) Pakrasi , 2005) وجيلبرت وياردن (Gelbart \& Yarden, 2006) التي هدفت إلى التعرف على فاعلية استخدام بيئة تعلم قائمة على استخدام شبكة الإنترنت في المعلوماتية الحيوية في مادة الأحياء بالمرحلة الثانوية، ودراسة زانج (Zhang, 2009) التي اهتمت بالتحقق من فاعلية مدخل جديد لتدريس المعلوماتية الحيوية باستخدام التسلسلات الجينية لنبات الأرابيدوبسيس "Arabidopsis". 
وهناك العديد من الدراسات التي اهتمت بتحليل المناهج الدراسية للتعرف على مدى

تضمينها للمعلوماتية الحيوية، مثل: دراسة ويفر وشيبارد (Wefer\& Sheppard, 2008) التي هدفت إلى تحليل معايير العلوم البيولوجية بالمدرسة الثانوية لتسع وأربعين ولاية من الولايات المتحدة الأمريكية، وذلك فيما يتعلق بالمحتوى المرتبط بالمعلوماتيـة الحيوية، ودراسـة راملوو وماككونيل ودوان ومور (Ramlo, Mc Connell, Duan \& Moore, 2008) التي هدفت إلى تقييم الدقرر الدراسي للمعلوماتية الحيويـة القائم على الاستقصـاء، ودراسـة فورج وتروس ومور ولانجلاند (Furge, Truss, Moore \& Langeland, 2009) التي استهدفت التعرف على مدى تضمين المعلوماتيـة الحيويـة فـى محتوى مقرر العلوم الطبيعيـة بكليـة كالامـازو . Kalamazoo College

ويتضح مما سبق عرضـه أن المعلوماتية الحيويـة تعد جزيًا لا يتجزأ من علوم الحياة

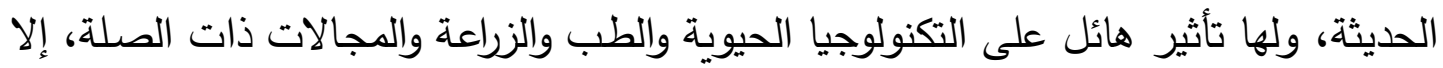
أنه نادرًا ما يتم دمجها في برامج تعليم وتعلم الأحياء بالمرحلة الثانوية، وليس لها دور في إعداد الجيل القادم من المواطنين الموجهين نحو المعلوماتية. , Machluf \& Yarden ,2013) (648 ، وذلك على الرغم من تأكيد الأهداف العامة لمنهج الأحياء بالمرحلة الثانويـة ضـرورة

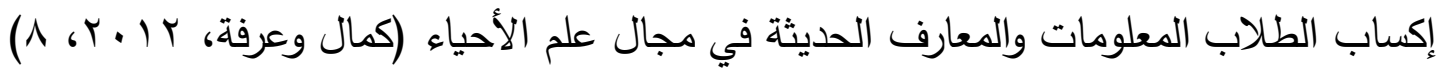
وتؤكد المعايير القومية للتعليم في مصر ضرورة أن يعرف طلاب المرحلة الثانوية في مادة الأحياء بعض تطبيقات التكنولوجيا الحيوية (التلقيح الصناعي - أطفال الأنابيب - تجميد

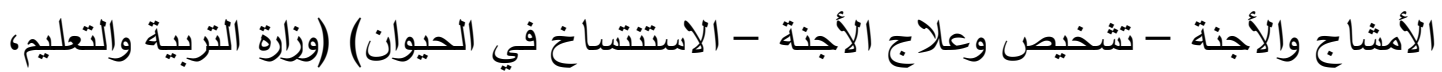

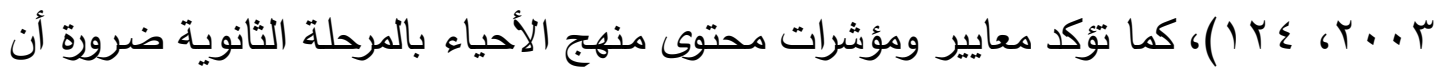
يفهم الطلاب مبادئ الهندسة الوراثية، وأهم تطبيقاتها في مجالات الزراعـة والصناعة والبيئة والطب والحروب، ودور التكنولوجيا الحيوية في الصناعات الغذائية وإنتاج المضادات الحيوية

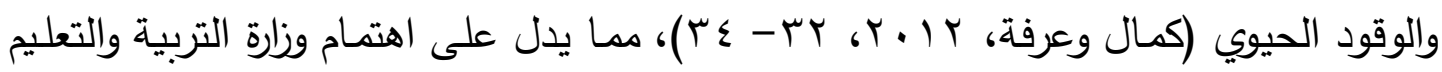

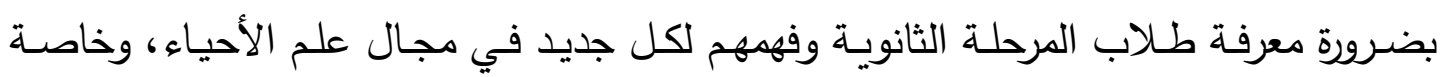
المعلوماتية الحيوية كأحد فروع الأحياء الحديثة. 
وبناءً على ما سبق كان من الضروري توجيه الاهتمام نحو منهج الأحياء بالصف الثالث بالمرحلة الثانوية ومراجعته وتقييمه في إطار تناوله للمعلوماتية الحيوية وتطبيقاتها. ومن هنا جاءت الحاجة للقيام بالبحث الحالي الذي يستهدف تقييم منهج الأحياء بالصف الثالث الثانوي في ضوء جاءت تناوله للمعطوماتية الحيوية وتطبيقاتها. ويحاول البحث الحالي التصدي لهذه المشكلة بالإجابة عن الأسئلة الآتية: 1 - ما مجالات المعلوماتية الحيوية وتطبيقاتها التي ينبغي تضمينها في منهج الأحياء

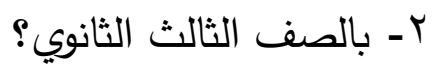
r- ما المعايير التي ينبغي توافرها في (أهداف ومحتوى) منهج الأحياء بالصف الثالث الثانوي ع - في ضوء مجالات المعلوماتية الحيوية وتطبيقاتها؟ هـ ما مدى توافر تلك المعايير في (أهداف ومحتوى) منهج الأحياء بالصف الثالث الثانوي؟ أهــاف البحـث وأهميتــه: إعداد قائمسة بمجالات المعلوماتية الحيوية وتطبيقاتها، وهذا قد يوجها إهتمام مخططي

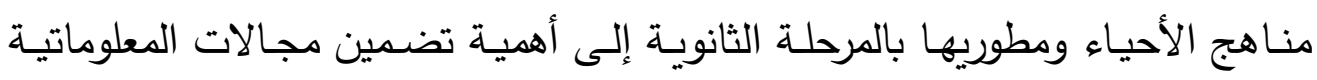
الحيوية وتطبيقاتها عند تطوير تلك المناهج. ه إعداد قائمة بمعايير الأهداف وبطاقة تحليل للأهداف، وقائمة بمعايير المحتوى, وبطاقة

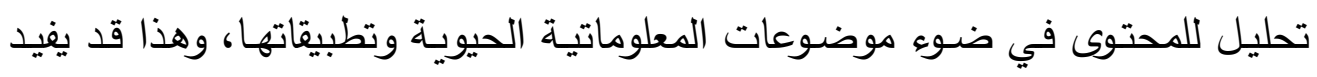
القائمين على بناء وتطوير المناهج في تقييم مكونات منهج الأحياء على أسس علمية.

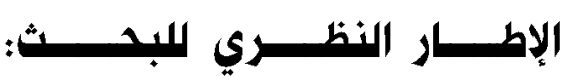

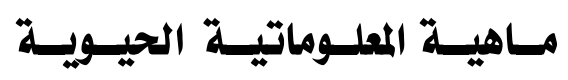

تضم المعلوماتية الحيوية معاني متعددة، ولقد استعرضت الأدبيات العديد من تعريفات المعلوماتية الحيوية، ومنها ما يلي:

استخدام تكنولوجيـا الحاسـب الآلكي لمســاعدة العلمـاء للاحتفاظ بالمعلومـات الجينيـة

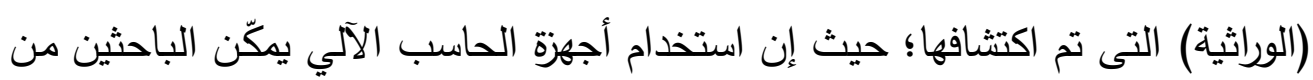


جمع وتخزين وتحليل ومقارنة البيانات بسرعة ودقة كبيرة، وتفسير واستخدام المعلومات من الجزيئات والتسلسلات البيولوجية. (Raza, 2010, 114)

مزيج من العلوم البيولوجية وعلوم الحاسب الآلي وتكنولوجيا المعلومات، وهي فرع من العلوم يتناول العديد من مجالات العلوم البيولوجية، وخاصة مجالات علم الأحياء الحديث، ومنها علم الجينوم، وعلم البروتيوم، وعلم الوراثة، والتطور • (Kovarik et al., 2013, 442) مزيج من العلوم البيولوجية وعلوم الحاسب الآلي وتكنولوجيا المعلومات، وهي فرع من العلوم يتناول العديد من مجالات العلوم البيولوجية، وخاصة مجالات علم الأحياء الحديث، ومنها علم الجينوم، وعلم البروتيوم، وعلم الوراثة، والتطور . (Kumar \& Chordia, 2017, 1)

\section{الأسس البيولوجية للمعلوماتية الحيوية}

تقوم المعلوماتية الحيوية على عدة أسس بيولوجية منها علم الجينوم، وعلم البروتيوم، وبيولوجيا النظم، وفيما يلي شرح نبذة لكل منها:

\section{أورةً: علـــمالجبي: Genomics}

يُعرف علم الجينوم بأنه فرع من فروع العلوم البيولوجية الذي يتعامل مع تركيب المعلومات المشفرة أو المرمزة فى جينوم الكائنات الحية، أي في التسلسلات الكاملة للحمض النووي للكائنات الحية، ويهتم علم الجينوم بدراسة الجينومات، حيث تتميز الدراسات التي تم إجراؤها في مجال الجينوم بالتحليل المتزامن لعدد كبير من الجينات عن طريق الاستخدام الآلي لأدوات جمع البيانات، كما يتضمن علم الجينوم موضوعات متعددة منها رسم خرائط (Xiong, 2006, 243). الجينوم، والتسلسل، وتحليل الجينوم الوظيفي، وتحليل الجينوم المقارن

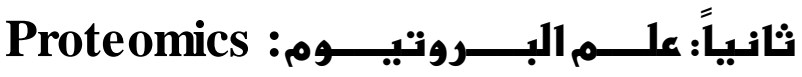

هو العلم الذي يهتم بدراسة البروتينات، من حيث موقعها وتركيبها ووظيفتها، حيث يتم تحديد وتقدير جميع البروتينات المتضمنة أو المشاركة في مسار معين، عضية، وخلية، ونسيج، وعضو أو كائن، وهذه البروتينات يمكن أن توفر بيانات دقيقة وشاملة عن هذا النظام، كما يتعامل مـع كل البروتينات الموجودة في أي خلية والتفاعلات بين هذه البروتينات، والوصف التركيبي لها.(Fulekar, 2009, 208)( 


\section{ثنالثًا: الأنظمـة البيـورهـويـة Systems biology}

in تُعرف الأنظمة البيولوجية بأنها تحليل العلاقات بين العناصر في نظام استجابة Response to للنظام، وقد يكون هذا النظام بعض جزيئات البروتين المستخدمة لتنفيذ مهمة معينة، كما قد يثمل النظـام البيولوجي الجزيئات والخلايـا والأعضـاء والأفراد، أو حتى النظم الإيكولوجيـة (Weston \& Hood, 2004, 179).

\section{تطبيقــات المعلـوماتيــة الحيـويــة}

يوجد العديد من تطبيقات المعلوماتية الحيوية في المجالات البحثية المختلفة يتضح كما يلي:

\section{تطبيقات المعلوماتية الحيوية في البصمة الوراثية:}

يعتمد تحديد الهويـة الثخصـية على خصـائص متعددة منها الخصـائص البيولوجيـة (الحمض النووي، والدم، اللعاب، وما إلى ذلك)، وكذلك الخصـائص الفيسيولوجية (بصمات الأصابع، وقزحية العين وشبكيتها، واليدان، وملامح الوجه)، بالإضافة إلى الخصائص السلوكية (طريقة المشي، وحركة الثفاه، وتعبيرات الوجه) وخليط من الخصائص الفسيولوجية والديناميكة مثل الصوت. ولقد أصبح الحمض النووي من أهم سمات تحديد الهوية الثخصية، وذلك لأن جميع الاختلافات الوراثية التى يمكن الحصول عليها من خلال تعبير أجزاء فى الحمض النووى لهي (الجينـات) أو بعض شـرائح الحمض النووي، يمكن رصدها واستخدامها كأدلة أو علامـات

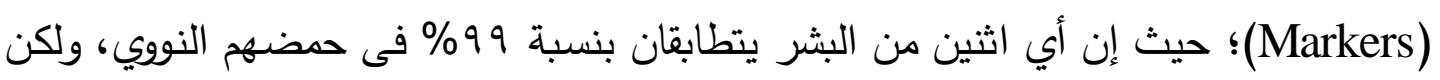

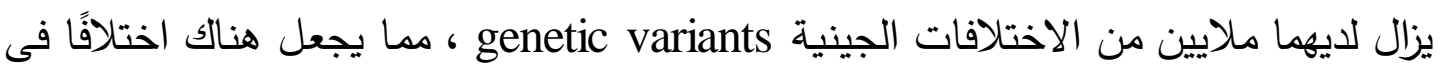
مدى إصابتهما ببعض الأمراض واستجابتهما للعوامل البيئية.(Bianchi \& Lio, 2007, 118)

\section{تطبيقات المعلوماتية الحيوية في علد الجينوم الميكروبي:}

تستخدم المعلوماتية الحيوية فى علم الجينوم الميكروبي في مجالات: تنظيف النفايات،

وتغيير المناخ، والطاقة البديلة.(Priyadarshi, 2014 ) 


\section{تطبيقات المعلوماتية الحيوية في التكنولوجيا الحيوية:}

يؤكد تراينور وفريديرك وكوش (Traynor, Frederick, Koch, 2002, 3) أن التقدم

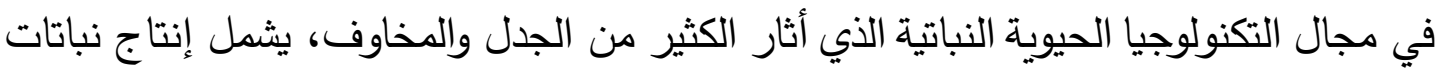

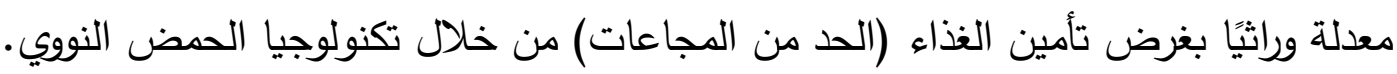

\section{تطبيقات المعلوماتية الحيوية في مجال الزراعة:}

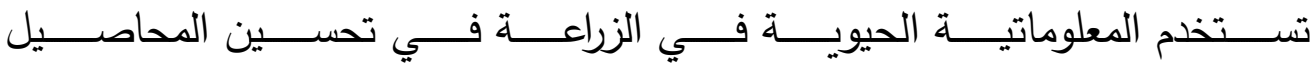

Crop Improvement للجفاف Development of Drought Resistance Varieties، وتحسين الجودة الغذائية (Priyadarshi, 2014 ) . Improve Nutritional Quality

\section{الاتجاهات العالمية لتضمين المعلوماتية الحيوية في المناهج الدراسية}

من الضروري أن نميز بين المناهج الدراسية المصممة لتدريس أساسيات المعلوماتية الحيوية وتلك التي تستخدم المعلوماتية الحيوية كأداة تدريسية، و يوجد العديد من دول العندية العالم التي اتجهت لتضمين المعلوماتية الحيوية في المناهج الدراسية بالمرحلة الثانوية، ومن هذه الدول: البرتغال(*) (Bioinformatics at Schools, Portugal ) يتم تدريس المعلوماتية الحيوية في المدارس الثانوية، حيث يتم تضمين مجموعة من الأنثطة في منهج علوم الحياة، ومن هذه الأنثطة نشاط علم الوراثة، ونشاط شجرة النشوء والتطور، ونشاط اكتثاف سر الجين،

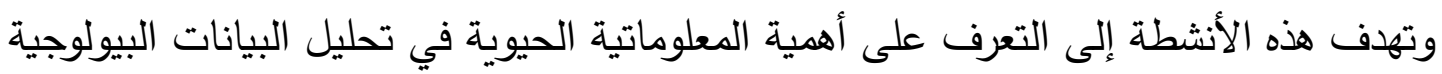

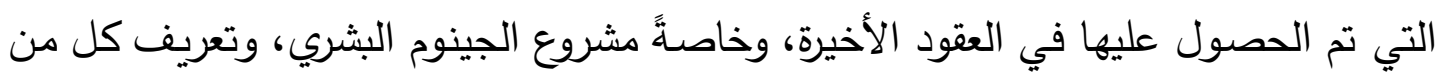
المعلمين والطلاب بطرق البحث الجديدة عن المعلومات البيولوجية باستخدام العديد من المصادر

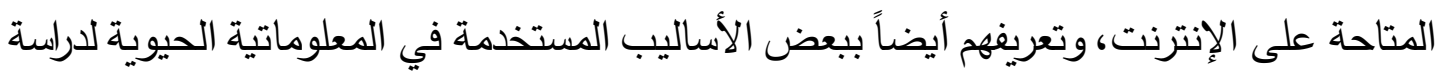
المشكلات البيولوجية، وجعل الأنشطة العملية في منهج علوم الحياة أكثر فاعلية.

(*) تم التوثيق في قائمسة المراجع الجزء الخاص بالمواقع الإكترونية التي تناولت الاتجاهـات العالمية لتضمين المعلوماتية الحيوية في المناهج الدراسية. 
وفي هولندا (Bioinformatics @ School Netherlands) يتم تدريس المعلوماتية الحيوية في المرحلة الثانوية، حيث يتم تضمين عدة وحدات دراسية خاصة بالمعلوماتية الحيوية في منهج الأحياء تتضمن هذه الوحدات، الوحدة الأولى بعنوان "البنوك الحيوية" والتي تتناول أمثلة للبيانات البيولوجيـة التي يمكن تخزينها في قواعد البيانات، مثل: نوع الدم وتثوهات الحمض النووي وقواعد البيانات الجنائية حيث ترتبط ملفات الحمض النووي بالجرائم بحيث يمكن العثور على الجاني بطريقة سريعة، والوحدة الثانية بعنوان "التصميم" تتناول تصميم مضاد للسموم حيث يقوم فيها الطلاب باجراء تجارب بسيطة تعطي صورة بصرية واضحة عن كيفية عمل الإنزيمات وتصميم مضـاد للسموم ثلاثي الأبعاد، أمـا الوحدة الثالثة وعنوانها "التطور" تتناول البروتينات المتماثلة ووظيفة كل بروتين وشجرات النشوء والتطور للكائنات الحية، والوحدة الرابعة بعنوان "جريمة قتل في المطار" وفيها يتم التحقيق في جريمة قتل أحد الأشخاص وذلك رديك عن طريق عزل أربع بروتينات يشتبه بها واستخدام قواعد البيانات المتاحة على شبكة الإنترنت للتعرف على هذه البروتينات وتحديد البروتين المتسبب في قتل الثخص وهو بروتين سم الثعبان الموجود في اللبن الذي تناوله الثخص المقتول.

وفي إسرائيل: يتم تضمين المعلوماتية الحيوية ضمن منهج التكنولوجيا الحيوية بالمرحلة

الثانوية، حيث تمثل إحدى وحدات منهج التكنولوجيا الحيوية، ويتم تناول عدة موضوعات، منها: أدوات المعلوماتية الحيويـة المستخدمة على نطاق واسـع من قبل العلماء، والتي تساعد على اكتساب الممارسات الرئيسة للمعلوماتية الحيوية، مثل محاذاة التسلسلات، وتصميم البادئات Prediction لتفاعل البلمرة المتسلسل، والتنبؤ بأطر القراءة المفتوحة في تسلسل نيوكليوتيد معين of Open Reading Frames in a Given Nucleotide Sequence الأحماض الأمينية، البحث عن مجالات البروتين والمواقع الوظيفية، وتصور التركيب ثلاثي الأبعاد للجزيئات، وكل هذه الموضوعات مرتبطة ارتباطا وثيقا بالمعارف والمهارات في منهج (Machluf, Gelbart, Ben-Dor \& Yarden, 2016, 3). التكنولوجيا الحيوية 


\section{البدراسبات السـابـة}

اهتم بعض الدراسات والبحوث بتقويم مقرر المعلوماتية الحيوية وتحليل وتقويم المناهج الدراسية للتعرف على مدى تضمينها للمعلوماتية الحيويـة مثل دراسة راملو وماك كونيل ودوان ومور (Ramlo, McConnell, Duan and Moore, 2008) التي هدفت إلى تقييم المقرر Question ) الدراسي للمعلوماتية الحيوية القائم على الاستقصاء باستخدام منهجية طرح الأسئلة Methodology)، وذلك لتحديد وجهات نظر (آراء) طلاب المرحلة الجامعية بجامعة أكرون بالولايات المتحدة الأمريكية The University of Akron حول مقرر المعلوماتية الحيوية لإنخال تعديلات على المقرر وفقًا لوجهات النظر، كما تم تدريس مقرر المعلوماتية الحيويـة القائم على الاستقصاء بواسطة متخصصي علم الحاسب الآلي، وعلم الوراثة التطوريـة، ثم تطبيق استبيان الأسئلة المكون من وج مفردة على المشاركين في الدراسة، وأشارت نتائج الدراسة إلى أن: منهجيـة طرح الأسئلة قد سـاعدت الباحثين على تقيسم وجهات نظر الطـلاب بشـأن تجاربهم في المعلوماتية الحيوية ضمن مقرر المعلوماتية الحيوية القائم على الاستقصاء الذي يدرسه الطلاب الجامعيون وطلاب الدراسات العليا على حد سواء. طرق وأساليب التقييم الكيفية مثل المقابلات الفردية تستغرق وقتاً أطول من منهجية طرح الأسئلة.

ودراسة ويفر وشيبارد (Wefer \& Sheppard, 2008) هدفت إلى تحليل معايير العلوم البيولوجية بالمدرسة الثانويـة لتسع وأربعين ولايـة من الولايات المتحدة الأمريكية، وذلك وديك فيما يتعلق بالمحتوى المرتبط بالمعلوماتية الحيوية، وقد تم تحليل محتوى العلوم البيولوجية بكل ولاية في ضوء (9) محاور رئيسة وهي: مشروع الجينوم البشري وعلم الجينات - الطب الثرعي - التطور - التصنيف - الاختلافات النيكليوتيديـة - الطب - استخدام الكمبيوتر - الزراعـة وتكنولوجيا الغذاء - القضايا العلمية الاجتماعية ( العلم والتكنولوجيا والمجتمع )، وقد أوضحت النتائج التمثيل المتذني للمحتوي المرتبط بالمعلوماتية الحيوية بصفة عامة، والذي اختلف بين المحاور التسعة حيث كان مشروع الجينوم البشري وعلم الجينات وكذلك استخدام الكمبيوتر أقل نسبة (^^\%)، والتطور أعلى نسبة (ء ٪\%)، وقد أوصـت الدراسـة بمراجعـة وتحديث المعايير الموجودة وذلك لتسهيل هدف تدعيم التنور العلمي لطلاب المدرسة الثانوية. 
(Furge,Truss, Moore and Langeland, ودراسة فورج وتروس ومور ولانجلاند (2009 التي استهدفت التعرف على ددى تضمين المعلوماتية الحيوية في محتوى مقرر العلوم الطبيعية بكلية كالامازو Kalamazoo College، وكذلك التعرف على مدى استفادة الطلاب الخريجين منها، ومن خلال تحليل محتوى تلك المقررات وتطبيق استطلاع رأي على مجموعة

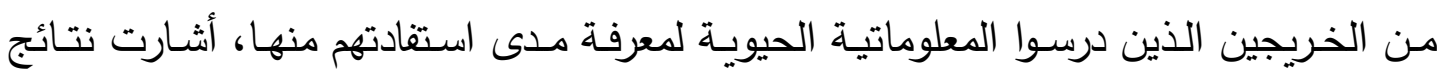

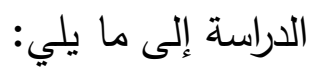

\section{أولاً تتر تضمين المعلوماتية الحيوية في شكل وحدات في المقررات الآتية:}

في قسم الأحياء تم التضمين في مقررات (التطور والوراثة - الخلية والبيولوجيا الجزيئية

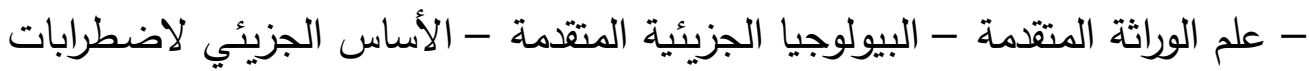

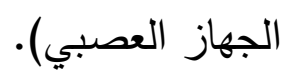

في قسم الكيمياء تم التضمين في مقررات (الكيمياء التمهيدي - الكيمياء الحيويـة الكيمياء الحيوية المتقدمة - مبادئ الكيمياء الطبية).

في قسم الحاسب الآلي تم التضمين في مقررات (مقدمة للحوسبة العلمية - تراكيب البيانات - مقدمة لتعلم الآلة).

في قسم الرياضيات تم التضمين في مقرر المعادلات التفاضلية والطرق العددية. في قسم الفيزياء تم التضمين في مقرر مقدمة للأنظمة المعقدة.

\section{ثانياً : الطلاب الخريجين يستخدمون المعلوماتية الحيوية}

في مواضـع مختلفة diverse settings، كما أنهم استفادوا من دراستهم للمعلوماتية الحيوية في المرحلة الجامعية في منهج الكيمياء الحيوية والبيولوجيا الجزيئية في إعدادهم المهني. وأجرت (أبو حية، ب ـ ب) دراسة لتحديد مستوى فهم تطبيقات البيومعلوماتية ومستوى اتجاهات معلمي الأحياء بالمرحلة الثانوية بقطاع غزة نحو هذه التطبيقات، ولتحقيق ذلك قامت

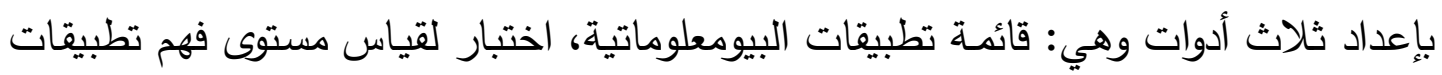
البيومعلوماتية، ومقياس اتجاه معلمي الأحياء نحو تطبيقات البيومعلوماتية، ث طبقت الاختبار 
والمقياس على عينة مكونة من (T) Y T) معلمًا ومعلمة للأحياء بالمرحلة الثانوية بقطاع غزة،

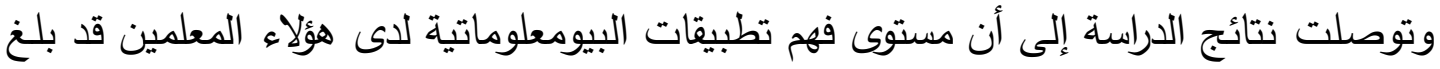

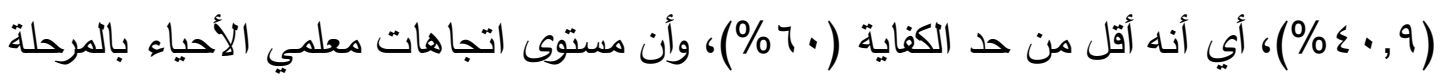

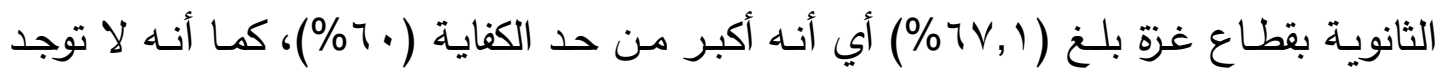

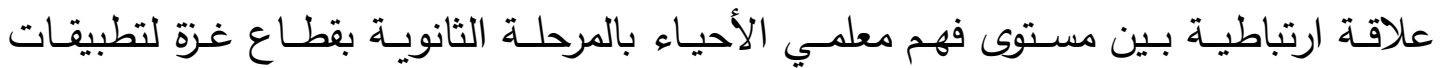

$$
\begin{aligned}
& \text { البيومعلوماتية ومستوى اتجاهاتهم نحوها. } \\
& \text { تعقـيب على الــدراسـات السـابةـة }
\end{aligned}
$$

أكدت الدراسات السابقة على أهية المعلوماتية الحيوية وتطبيقاتها، وضرورة تضمين مناهج المرحلة الثانوية بالمعلوماتية الحيوية وتطبيقاتها.

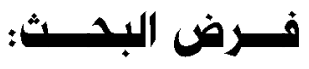

"الا يتضمن منهج الأحياء بالصف الثالث بالمرحلة الثانوية (الأهداف - المحتوى) المعارف

والمعلومات المرتبطة بالمعلوماتية الحيوية وتطبيقاتها بالقدر المناسب وهو ما يمثل .ب \% \%".

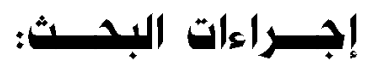

اتبع البحث الحالي الإجراءات التالية للإجابة على أسئلة البحث والتحقق من فرضه:

أولًا : إعلداد استطلاع رأي بـججالات المعلوماتيـة الحيويـة وتطبيقاتها التي ينبفي تضـمينها في منهج الأحياء بالصف الثالث بالمرحلة الثانوية.

للإجابـة عن السؤال الأول من أسئلة البحث وهو: مـا مجالات المعلوماتيـة الحيويـة

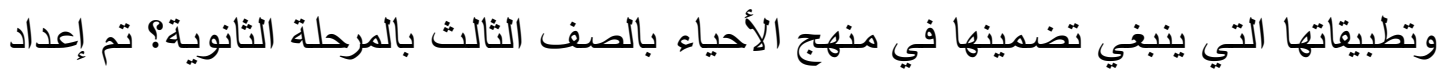
استطلاع رأي بمجالات المعلوماتية الحيوية وتطبيقاتها التي ينبغي تضمينها في منهج الأحياء بالصف بالمرحلة الثانوية، من خلال الخطوات الآتية:

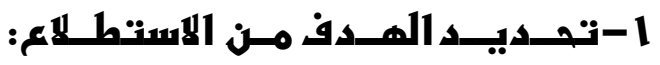

التعرف على مجالات المعلوماتية الحيوية وتطبيقاتها من حيث أهيتها ومدى مناسبتها

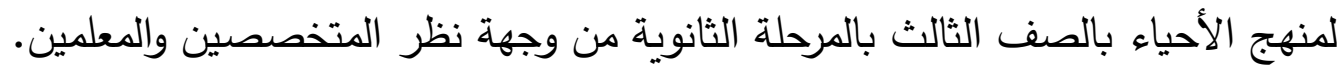




\section{r-مصـادر اشتقفـاق استطـلاع الـرأي (*):}

تم اشتقاق استطلاع الرأي الخاص بالمعلوماتية الحيوية وتطبيقاتها من عدة مصادر:

$$
\text { بعض المراجع التى تناولت المعلوماتية الحيوية. }
$$$$
\text { الدراسات والبحوث السابقة وما توصلت إليه من نتائج. }
$$

بعض المواقع الإلكترونية المتخصصة ذات الصلة بالمعلوماتية الحيوية.

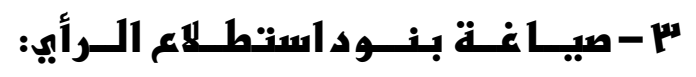

تمـت صـياغة بنود استطلاع الرأي في صسورة عبارات وأمسام كل عبارة مستويان،

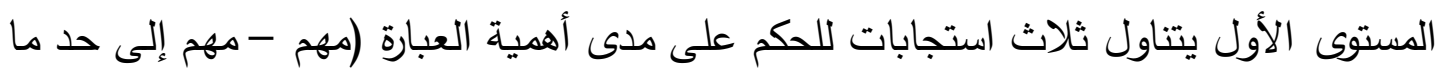

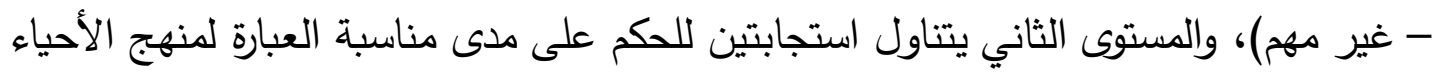

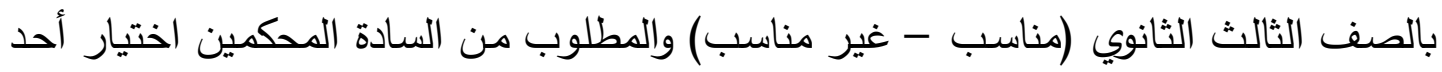

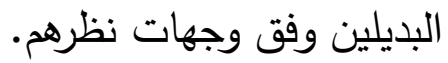

\section{ع-الصــورة الأوليــة لاستطــلاع الــرأي:}

اشتملت الصورة الأولية للاستطلاع (")على • با بندًا.

\section{0-ضبـــاستطـــاع الــرأي:}

تم عـرض استطلاع الـرأي في صـورته الأوليـة على مجموعـة مـن السـادة الخبـراء والمحكمين (" *من أعضاء هيئة التدريس بكليات الطب البشري والطب البيطري والعلوم والزراعة

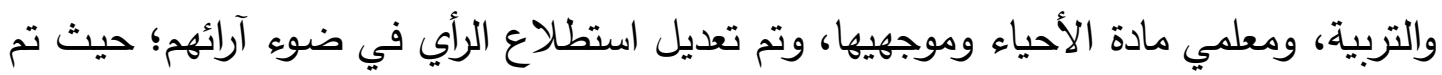

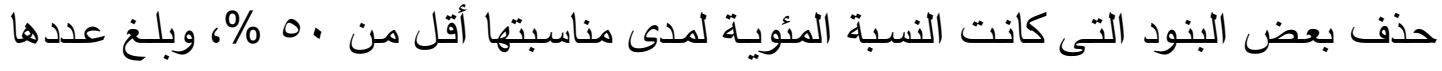

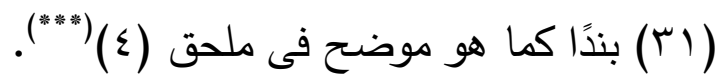
(*) ملحق (1) مصادر اشتقاق استطلاع الرأي.

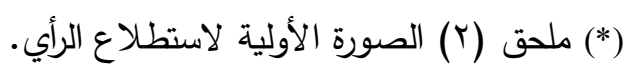

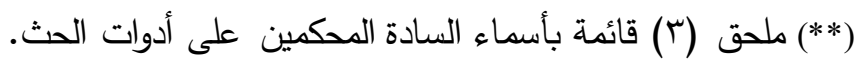
(****) ملحق (ع ) تكرارات درجة الأهمية ومدى المناسبة والنسبة المئوية لبنود الاستطلاع الخاص الهاص بالمعلوماتية الحيوية وتطبيقاتها. 
بعـد إجـراء التعـديلات وحـذف بعـض البنـود أصــبح الاســطلاع فـي صــورته

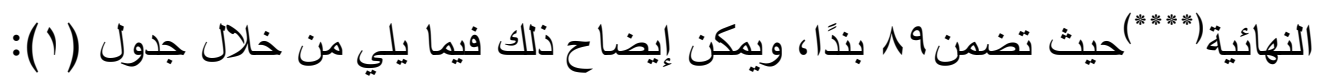

جلول (1) علد بنود استطلاع الرأي في الصورة الأولية والنهائية

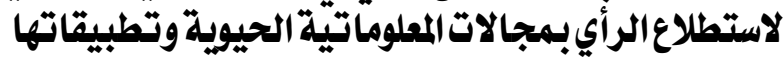

\begin{tabular}{|c|c|c|c|c|}
\hline عدد البنود في الصورة النهائية & عدد البنود التي & الصدد البنود في & جــــوانـــب استطـــلاع الــــرأي & هـ \\
\hline 9 & - & 9 & ماهية المعلوماتية الحيوية ونشأتها ونوعيهاوفروعها. & 1 \\
\hline 11 & - & 11 & |مجالات المعلوماتية الحيوية & $r$ \\
\hline$\varepsilon$ & - & $\varepsilon$ & |مفاهيه مرتبطة بالمعلوماتية الحيوية & $r$ \\
\hline- & ir & ir & |قواعد بيانات المعلوماتية الحيوية & $\varepsilon$ \\
\hline- & $\wedge$ & $\Lambda$ & أدوات المعلوماتية الحيوية & 0 \\
\hline$\Lambda$ & 1 & 9 & |مجال الطب الجزئئي & 7 \\
\hline 9 & 1 & 1. & | مجال علد الجينوه الميكروبي & v \\
\hline$r$ & - & $r$ & |مجال تقيييه المخاطر & $\wedge$ \\
\hline$\varepsilon$ & 1 & 0 & |مجال التطور والطفرات & 9 \\
\hline 9 & - & 9 & مجال الحمض النووي وعله الطب الشرعي & 1. \\
\hline 9 & - & 9 & |مجال الزراعة والثروة الحيوانية & 11 \\
\hline r & 1 & $r$ & |مجال اللراسات المقارنة & ir \\
\hline r & - & r & | مجال الحرب البيولوجية & it \\
\hline ir & $r$ & 10 & |مجال عصر ما بعد الجينوم & is \\
\hline$\varepsilon$ & - & $\varepsilon$ & |مجال التكنولوجيا الحيوية & 10 \\
\hline r & $r$ & 7 & | مجال النانو تكنولوجي & 17 \\
\hline 19 بند & ri & ir. & 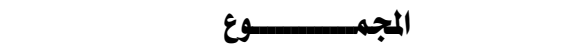 & \\
\hline
\end{tabular}

لم يتم حذف (0) بند على الرغم من أن مدى مناسبتها كان أقل من 0 \% وذلك لأسباب مختلفة يمكن إيجازها في الجدول التالي: 


\begin{tabular}{|c|c|c|}
\hline 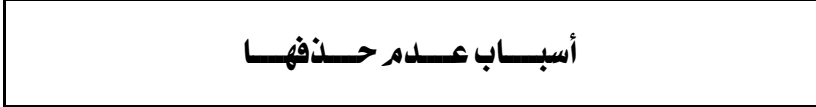 & 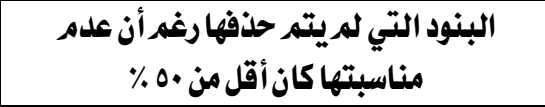 & ه \\
\hline 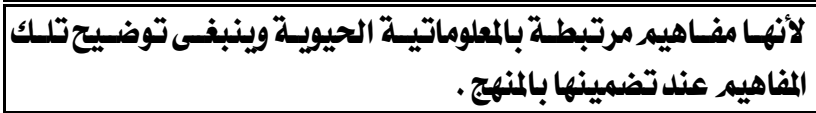 & والأحياء الحاءوبئية الجية أحياء الأنظمة الحاسوبية & 1 \\
\hline 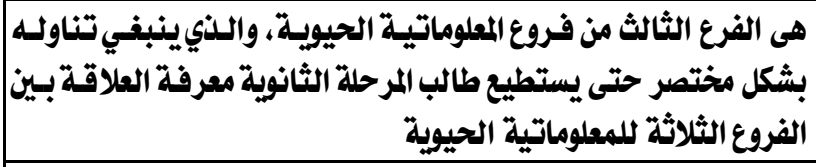 & بيولوجيا النظم & $r$ \\
\hline أحلحد تطبيقـات مجـال الطب الجزيئسي ، ويعتـبر متطلبـا معرفيـا يسـبق & كل شخص الشخصي القائم على جينـات وبروتينـات & $r$ \\
\hline 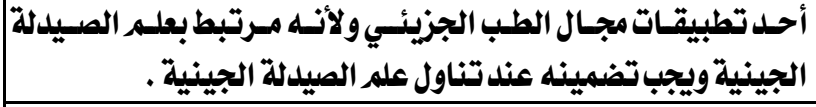 & اسب مع جينات المريض & $\varepsilon$ \\
\hline 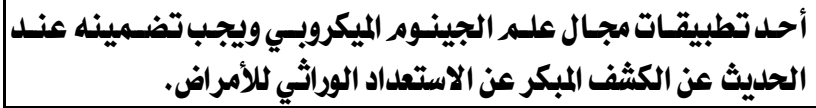 & 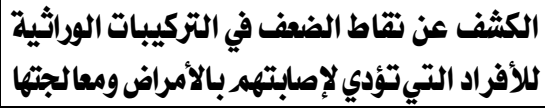 & 0 \\
\hline 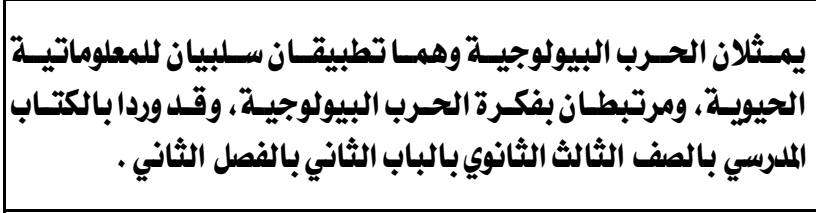 & 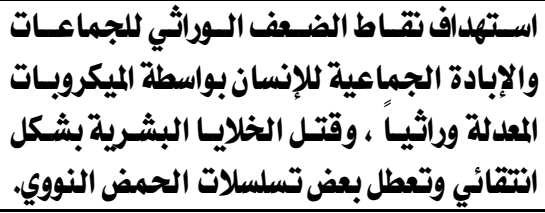 & 7 \\
\hline 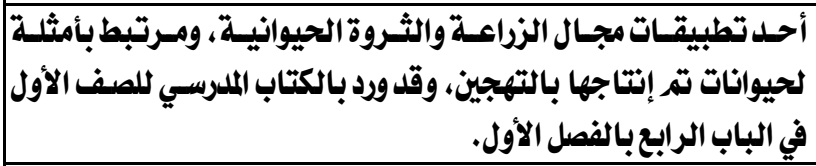 & 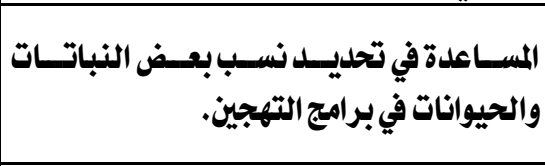 & $\mathbf{v}$ \\
\hline 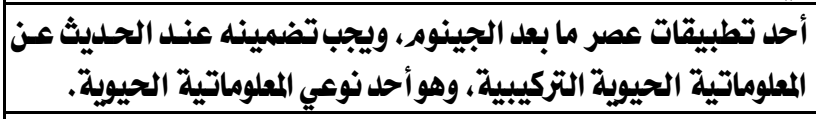 & التنبؤ بالتركيب ثلاثي الأبعاد للجينومر معتملًا & $\Lambda$ \\
\hline 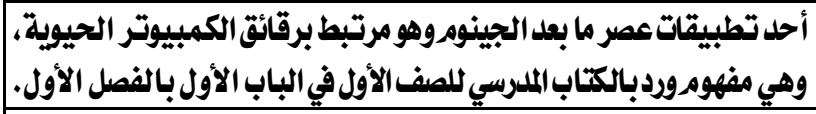 & الكمبيوترية. الدماغ بالكمبيوتر مـ خلال زرع الرقائق & 9 \\
\hline 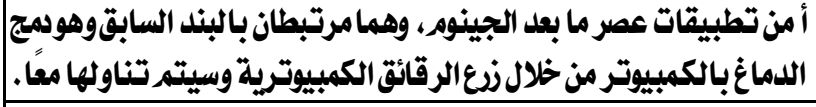 & 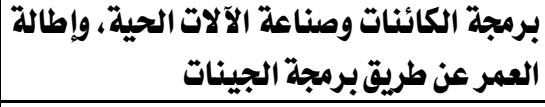 & 1. \\
\hline 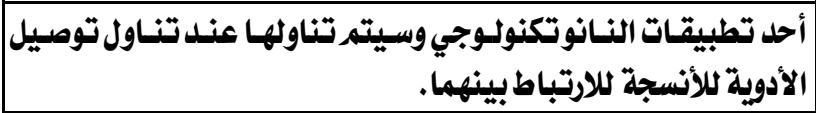 & 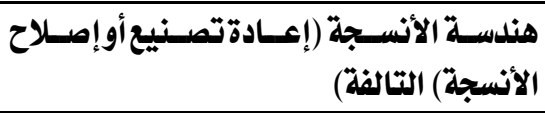 & 11 \\
\hline
\end{tabular}

ثانيًا : إعداد قائمتين بالمعايير التي ينبفي مراعاتها في أهداف ومحتوى منهج الأحياء بالصف الثالث بالمرحلة الثانوية في ضوء استطلاع الرأي بمجالات المعلوماتية الحيوية وتطبيقاتياتها.

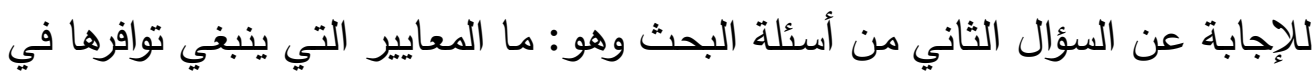

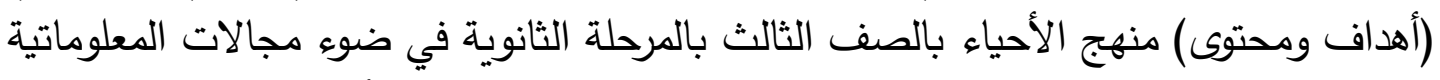

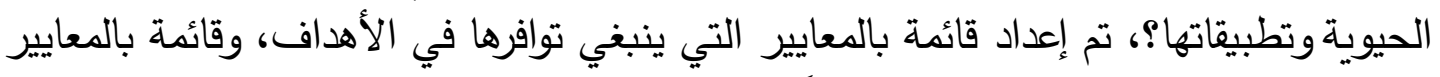

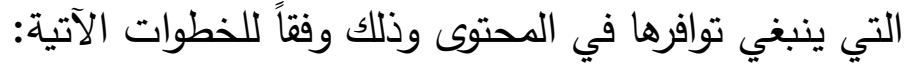


1 - قائمة معايير الأهداف في ضوء مجالات المعلوماتية الهيوية وتطبيقاتها:

تم إعداد قائمة بالمعايير التي ينبغي توافرها في أهداف منهج الأحياء بالصف الثالث بالمرحلة الثانوية في ضوء مجالات المعلوماتية الحيوية وتطبيقاتها وذلك كالتالي:

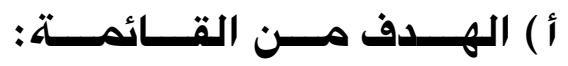

تهاف القائعة إلى تحديد المعايير الخاصة بالأهداف المعرفية والمهارية والوجدانية التي

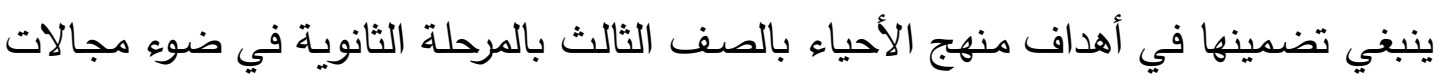
المعلوماتية الحيوية وتطبيقاتها.

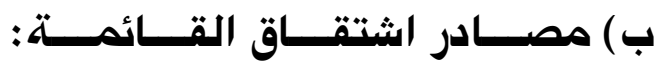

تم إعاد قائمة معايير الأهداف في ضوء مجالات المعلوماتية الحيوية وتطبيقاتها اعتماداً على: • استطلاع الرأي الخاص بمجالات المعلوماتية الحيوية وتطبيقاتها. بعض الدراسات والبحوث السابقة التي اهتمت بتضمين مجالات المعلوماتية الحيويـة

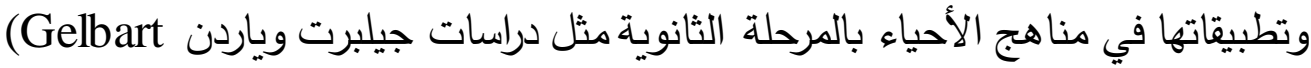

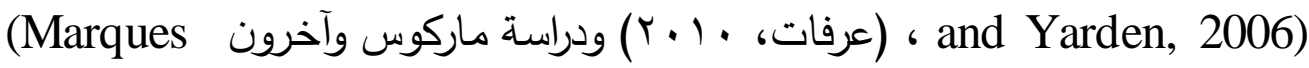

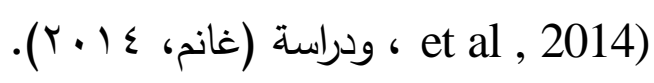
بعض المعايير الخاصة بمنهج الأحياء بالمرحلة الثانوية في مصر.

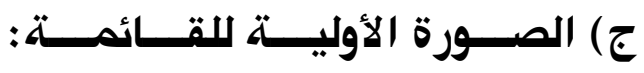

تم إعداد القائمة في صورتها الأولية حيث تناولت المعايير الخاصة بالأهداف المعرفية، وتم تقسيمها إلى المعايير الخاصـة بمفهوم المعلوماتيـة الديويـة وفروعها وهى ثلاثنة معايير ،

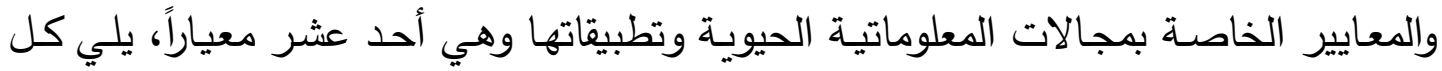
معيار المؤشرات الخاصة به، كما تم إعداد المعايير الخاصة بالأهداف المهارية والوجدانية.

\section{د) الصــورة النهــائيــة للقــائمسـة:}

تم عرض القائمة في صورتها الأولية على مجموعة من السادة المحكمين للحكم على

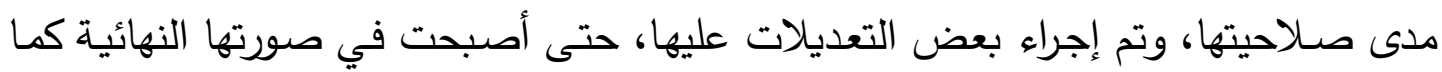

يتضح بملحق (T). 


\section{r - قائمة معابير المتتوى في ضوء مجالات المعلوماتية الهيوية وتطبيقاتها:}

تم إعداد قائمة بالمعايير التي ينبغي تضمينها في محتوى منهج الأحياء بالصف الثالث بالمرحلة الثانوية في ضوء مجالات المعلوماتية الحيوية وتطبيقاتها وذلك كالتالي:

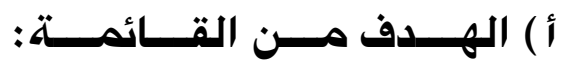

تهـدف القائمــة إلـى تحديد المعـايير الخاصــة بمحتوى مجـالات المعلوماتيـة الديويــــ وتطبيقاتها التي ينبغي تضمينها في محتوى مناهج الأحياء بالمرحلة الثانوية. ب) مصـــادر اشتقـــاق القـــائمـــة: تم إعداد قائهـة معايير المحتوى في ضـوه مجالات المعلوماتيـة الحيويـة وتطبيقاتها

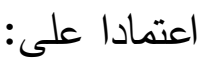

استطلاع الرأي بجالات المعلوماتية الحيوية وتطبيقاتها.

بعض الدراسات والبحوث السابقة التي اهتمت بتضمين مجالات المعلوماتية الحيوية

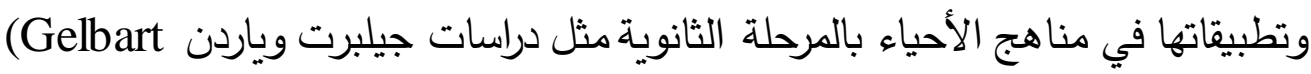

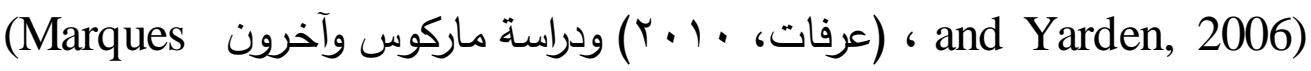

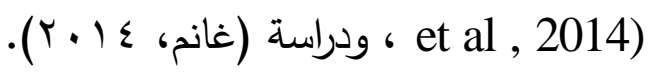
بعض المعايير المحلية و العالمية لمحتوى منهج الأحياء بالمرحلة الثانوية. ج) الصـــورة الأوليـــة للقـــائمـــة:

تم إعداد القائمة في صورتها الأولية حيث تناولت المعايير الخاصة بمحتوى مجالات

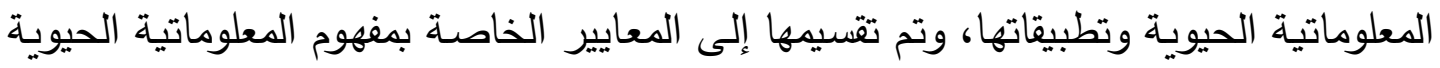
وفروعها، وهى ثلاثة معايير، والمعايير الخاصة بمجالات المعلوماتية الحيوية وتطبيقاتها وهي

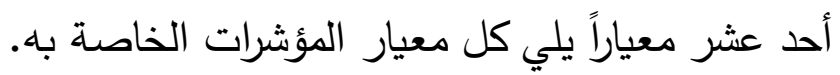

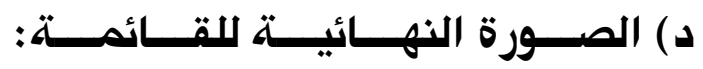

تم عرض القائمسة على مجموعـة من السـادة الدحكمين للحكم على مدى صـلاحيتها

وإعدادها في صورتها النهائية ملحق (V). 
ثالثًا : تحليل أهداف ومحتوى منهج الأحياء بالصف الثالث الثانوي وتقييمها في ضوء قائمتي المعايير (الأهداف والمحتوى)

للإجابة عن السؤال الثالث: ما مدى توافر تلك المعايير في (أهداف ومحتوى) منهج الأحياء بالصف الثالث بالمرحلة الثانوية؟ تم إجراء الخطوات التالية:

تم صياغة فرض البحث وهو لا يتضمن منهج الأحياء بالصف الثالث بالمرحلة الثانوية (الأهداف - الدحتوى) المعارف والمعلومات المرتبطة بالمعلوماتية الحيوية وتطبيقاتها بالقدر المناسب، وللتحقق من صحة هذا الفرض تم إجراء ما يلي:

\section{1- إعداد أداة تصليل أهداف منهمج الأصياء بالصف الثالث بالمرحلة الثانوية}

تم إعداد أداة تحليل أهداف منهج الأحياء بالصف الثالث بالمرحلـة الثانويـة وفق الخطوات التالية:

تحديد الهدف من أداة التحليل : استهدفت أداة التحليل الحكم على مدى تضمين أهداف

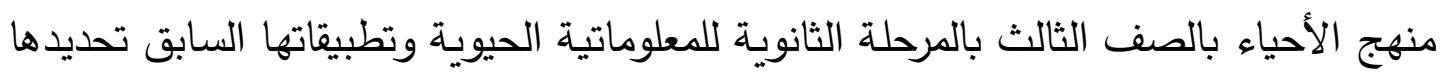

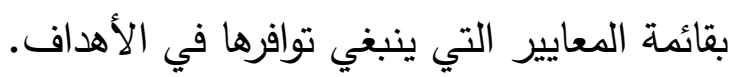

أ) الصـورة الأوليـتة لأداة التحليل: تم إعداد بطاقة لتحليل أهداف منهج الأحياء بالصف الثالث بالمرحلة الثانوية في ضوء قائمة معايير الأهداف السابق تحديدها.

ب) ضبط أداة التحليل: تم ضبط الصورة الأولية لأداة التحليل من خلال: ج) صـدق أداة التحليـل: حيث عرضت أداة التحليل على مجموعة من المحكمين، وذلك لإبداء الرأي حول إمكانية التحليل باستخدام تلك الأداة، وقد تم إجراء بعض الته التعديلات

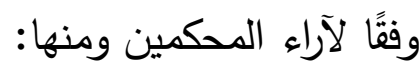

• إفافة بعض المؤشرات التى لها جانب وجداني ولم يتم تناولها في الجانب المعرفي.

$$
\text { • إعادة صياغة بعض المؤشرات. }
$$


د) الصورة النهائية لأداة التحليل: بعد إجراء التعديلات التى أشار إليها السادة الدحكمن،

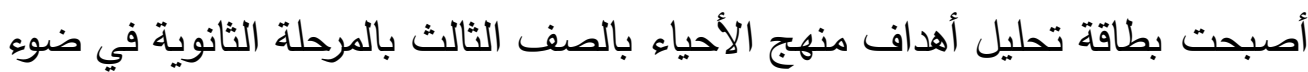
مجالات المعلوماتية الحيوية وتطبيقاتها في صورتها النهائية(").

\section{|r - إعداد أداة تمليل محتوى منهم الأصياء بالصف الثالث بالمرهلة الثانوية}

تم إعداد أداة تحليل محتوى مناهج الأحياء بالمرحلة الثانوية وفق الخطوات التالية: أ) تحديــد الهـدف مسن أداة التحليـل: استهدفت أداة التحليل الحكم على (مدى وشكل)

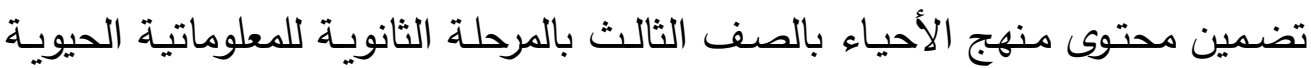
وتطبيقاتها السابق تحديدها بقائمة المعايير التى ينبغي توافرها في المحتوى. ب) الصورة الأولية لأداة التحليل: تم إعداد بطاقة لتحليل محتوى منهج الأحياء بالصف الثالث بالمرحلة الثانوية في ضوء قائمة المعايير التي ينبغي توافرها في المحتوى السابق تحديدها، وذلك لتحديد (مدى وشكل) تضمين المعلوماتية الحيوية وتطبيقاتها في محتوى منهج الأحياء.

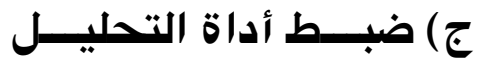

تم ضبط الصورة الأولية لأداة التحليل من خلال:

• صدق أداة التحليل: حيث عُرضت أداة التحليل على مجموعة من السادة المحكين؛ وذلك لإبداء الرأي حول إمكانية تحليل محتوى كتاب الأحياء بالصف الثالث بالمرحلة الثانوية باستخدام تلك الأداة، ولم تسفر عملية التحكيم عن أي تعديلات على أداة التحليل. • الصورة النهائية لأداة التحليل: أصبحت بطاقة تحليل محتوى منهج الأحياء بالصف الثالث : بالمرحلة الثانوية في ضوء مجالات المعلوماتية الحيوية وتطبيقاتها أيضاً في صورتها النهائية("). ץ- إجراءات التحليل: تم تناول إجراءات التحليل لكل أداة على حدة (أداة تحليل أهداف منهج الأحياء بالصف الثالث بالمرحلة الثانويـة، وأداة تحليل محتوى منهج الأحياء بالصف

(*) ملحق (^) بطاقة تحليل أهداف مناهج الأحياء بالمرحلة الثانوية في ضوء مجالات المعلوماتية الحيوية وتطبيقاتها.

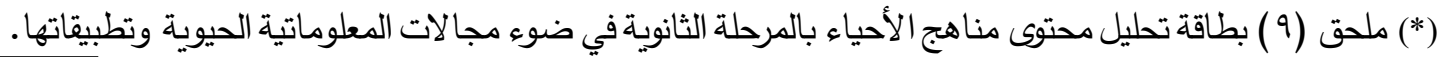


الثالث بالمرحلة الثانويـة) حيث إنـه بعد الانتهاء من إعداد أداة تحليل أهداف مناهج

الأحياء بالمرحلة الثانوية والتأكد من صلاحيتها للتطبيق تم القيام بالإجراءات التالية:

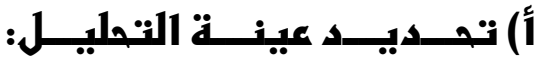

تحددت عينة التحليل في دليل المعلم وجميع الموضوعات الواردة بكتاب الأحياء للصف الثالث الثانوي، وذلك من خـلال تحديد المواصـفات العامـة لمحتوى أحدث طبعـة من كتاب الأحياء المقرر على طلاب الصف الثالث بالمرحلة الثانويـة.

تحديد وحدات التحليل: لتحديد مدى توافر بنود بطاقة التحليل في الأهداف في كل معيار تم التحليل في ضـوء الأهداف التى وردت في كل درس من دروس الصف الثالث

$$
\text { بالكتاب المدرسي أو دليل المعلم. }
$$

ب) تهديـد فئـات التهليـلـ: تعتبر المؤشرات المتضمنة في معـيير الأهداف فئات تحليل لأهداف منهج الأحياء بالصف الثالث بالمرحلة الثانويـة في ضوء مجالات المعلوماتية

$$
\text { الحيوية وتطبيقاتها. }
$$

م) ضوابـطالتمليل: تم الالتزام بالضوابط التالية:

تحليل موضوعات كتاب الأحياء - عينة التحليل - بما اشتمل عليه من صور ورسوم توضيحية وأنشطة.

تحليل أهداف كل موضوع من موضوعات الأحياء بالصف الثالث. د) ضبـط عملية التمليل: تم ضبط عملية التحليل من خلال حساب صدق التحليل وثباته كما يلي:

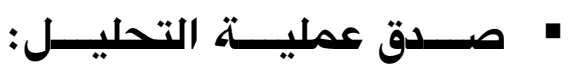

لتحديد صدق عملية التحليل قامـ الباحثة بتحليل أهداف ومحتوى منهج الأحياء بالصف الثالث بالمرحلة الثانوية باستخدام بطاقتي تحليل الأهداف والمحتوى، كما قامت إحدى

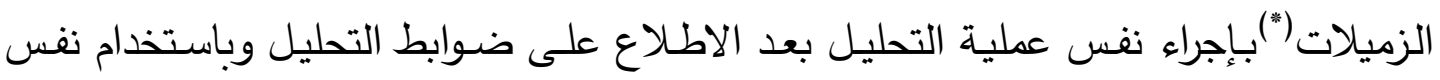
البطاقتين، وتم مقارنة نتائج تحليل الباحثة بنتائج تحليل الزميلة، وتم حساب نسبة الاتفاق من

(*) أ / رحاب جمال الدين الددرس المساعد بقسم المناهج وطرق تدريس العلوم البيولوجية والجيولوجية. 


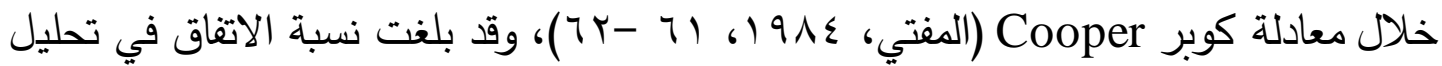

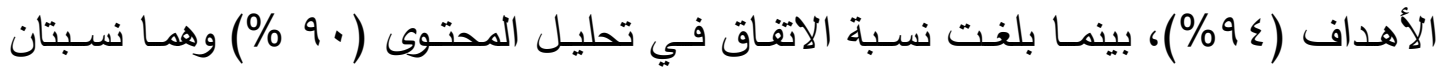

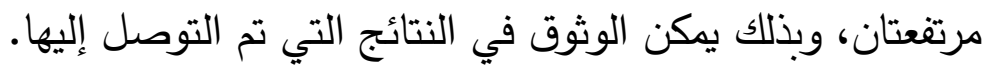

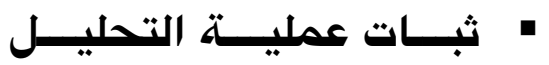

للتحقق من ثبات عملية التحليل قامت الباحثة بإجراء عملية التحليل مرتين متتاليتين

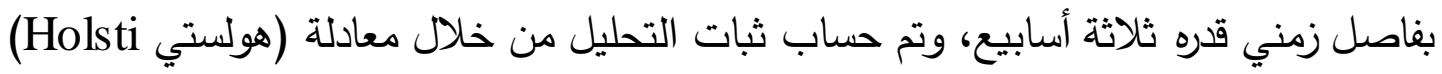

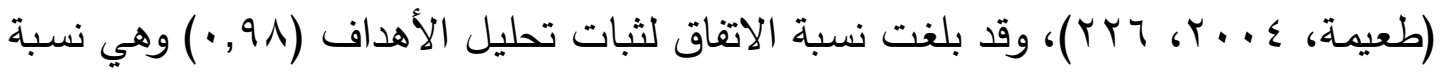

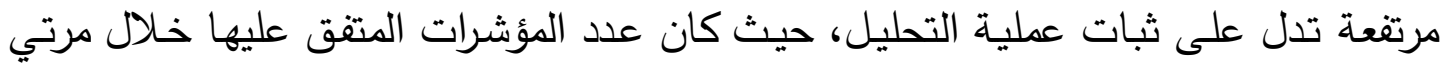

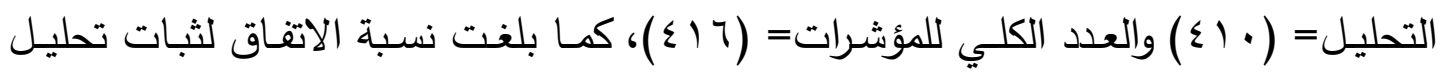
المحتوى (9 9 , •) وهي نسبة مرتفعة تدل على ثبات عملية التحليل، حيث كان عدد المؤشرات

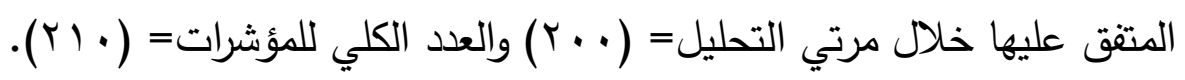

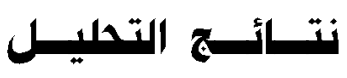

\section{أولاً : نتائج تحليل أهداف منهج الأحياء للصف الثالث الثانوي}

أسفرت عملية تحليل أهداف منهج الأحياء بالصف الثالث بالمرحلة الثانوية في ضوء تناولها لكجالات المعلوماتية الحيوية وتطبيقاتها وفقاً لقائعة المعايير التي تم إعدادها عن النقائ النتائج التالية:

\section{أ) نـتائج التصليل الكمي لأهداف منهم الأصياء للصف الثالث الثانوي}

حيث تم تحليل الأهداف الواردة بكتاب الطالب ودليل المعلم في ضوء قائمة معايير المعلوماتيـة الحيويـة وتطبيقاتها العدد الكلي لمؤشرات الجانب المعرفي فى معـايير

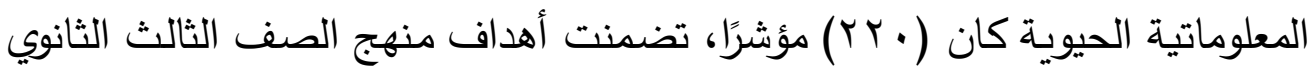
منها (V) مؤشرات فقط بنسبة r \% \%، وتثير هذه النتيجة إلى تدني مستوى تضمين أهداف المنهج للجانب المعرفي للمعلوماتية الحيوية.

العدد الكلي لمؤشرات الجانب المهاري فى معايير المعلوماتية الحيوية كان (ع T) مؤشرًا،

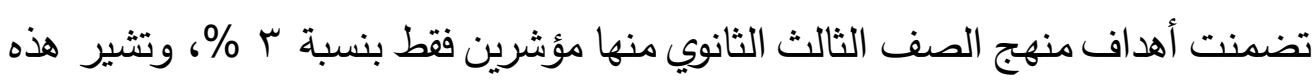
النتيجة إلى تدني مستوى تضمين أهداف المنهج للجانب المهاري للمعلوماتية الحيوية. 
العدد الكلي لمؤشرات الجانب الوجداني فى معايير المعلوماتية الحيوية كان (10)

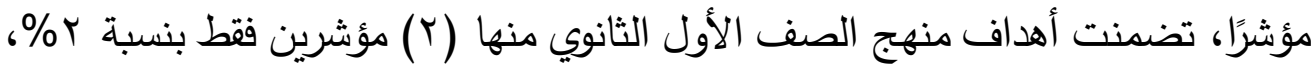

وتثير هذه النتيجة إلى التدني الثديد في مستوى تضمين أهداف المنهج للجانب

$$
\text { الوجداني للمعلوماتية الحيوية. }
$$

\section{ب) نتنائج التمليل الكيفي لأهداف منهم الأصياء للصف الثالث الثانوي}

من خلال فحص وتحليل أهداف منهج الأحياء للصف الثالث الثانوي لمعرفة مدى تضمينها لمعايير ومؤشرات المعلوماتية الحيوية وتطبيقاتها كما وردت في قائعة المعايير يلاحظ ما يلي:

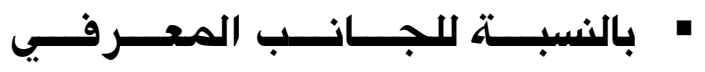

تضمنت أهداف المنهج أربعة مؤشرات فقط تحت معيار فروع المعلوماتية الحيوية وهى:

تحديد المقصود بالحمض النووي.

$$
\text { تعريف علم الجينوم. }
$$

ذكر تطبيقات مشروع الجينوم البشري حيث تعتبر أهمية الجينوم في مجال صناعة العقاقير هي أحد تطبيقات مشروع الجينوم البشري.

كما تضمنت أهداف المنهج ثلاثة مؤشرات فقط تحت معيار التطور والطغرات وهى:

$$
\begin{aligned}
& \text { تعريف الطفرة الوراثية. } \\
& \text { تحديد أنواع الطفرات. } \\
& \text { تفسير أسباب حدوث الطفرة. }
\end{aligned}
$$

ولم تتضمن الأهداف المعرفية للمنهج أى من المعايير والمؤشرات الآخرى.

وبناءً عليه يتضح تدني مستوى تضمين أهداف الجانب المعرفي في منهج الأحياء

للصف الثالث في ضوء قائمة المعايير · 


\section{• بالنسبـتة للجـانـب المهــاري}

تضمنت أهداف المنهج مؤشرين فقط هما:

• رسم جزئ الحضض النووي DNA المندرج تحت معيار نوعا المعلوماتية الحيوية.

فحص صور توضح شرائط البصمة الوراثية لإثبات البنوة أو نفيها المندرج تحت معيار

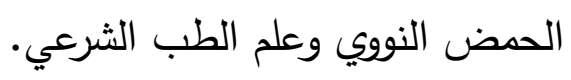

ولــم تتضــن الأهـداف المهاريـة لمـنهج الأحيـاء للصـف الثالـث أى مـن المعـيير

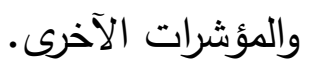

وهذا يثير إلى التدني الثديد في تضمين أهداف الجانب المهاري في منهج الأحياء

للصف الثالث في ضوه قائمة المعايير .

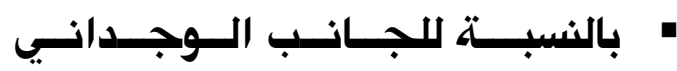

تضمنت أهداف المنهج مؤشرين فقط هما:

تقدير عظمة الخالق فيما يتعلق بالمعلومات الوراثية ودورها في تمييز البشر بصفات

تختلف من فرد لآخر الذي يندرج تحت معيار الحمض النووي وعلم الطب الشرعي.

الاهتمـام بالقضـايا الأخلاقيـة المرتبطــة بالتكنولوجيـا الحيويـة المنـدرج تحـت معيـار

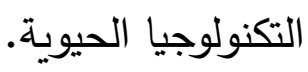

ولم تتناول الأهداف الوجدانية بالمنهج أى من المعايير والمؤشرات الآخرى.

وهذا يشير إلى التدني الثديد في تضمين أهداف الجانب الوجداني في منهج الأحياء

للصف الثالث في ضوء قائمة المعايير •

ثانياً: نتائج تحليل محتوى كتاب الأحيـاء بالصف الثالث الثانوي في ضوء مجالات المعلوماتيـة

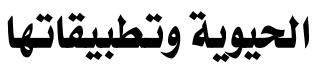

أسفرت عملية تحليل محتوى كتاب الأحياء بالصف الثالث بالمرحلة الثانويـة (طبعة

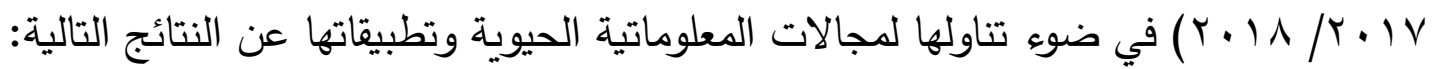


أ) نتنائج التمليل الكمي لمهتوى كناب الأصياء للصف الثالث الثانوي

العدد الكلي لمؤشرات المحتوى فى معايير المعلوماتية الحيوية كان (ع • †) مؤشرات،

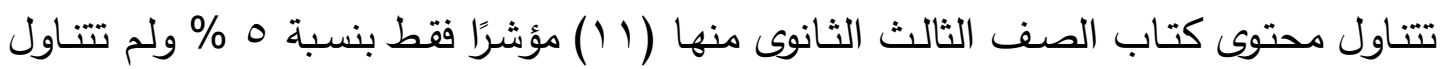

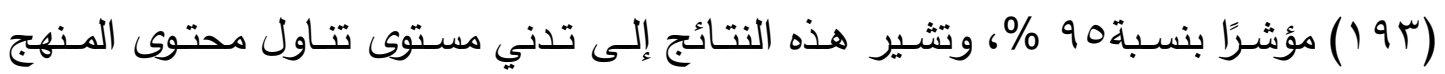

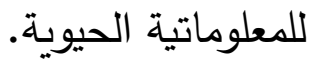

\section{ب) ومن خلال التحليل الكيفي المهتوى كتاب الأحياء للصف الثالث الثانوي يتضح ما يلي:}

لـ لم يتضـمن المحتوى أي مؤشر مـن مؤشـرات المعـايير التاليـة: المعلوماتيـة الحيويـة

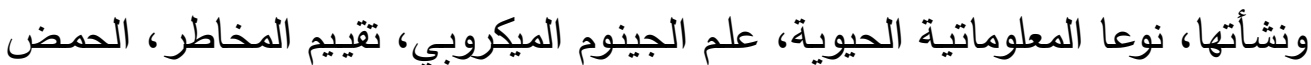

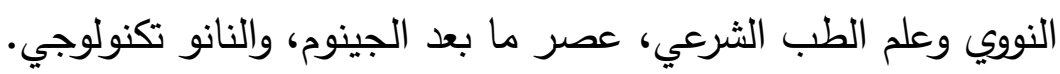

بينما تضمن المحتوى مؤشرين من معيار فروع المعلوماتية الحيوية وهما:

ا المقصود بالحمض النووي DNA وقد تم تتاوله بشكل تفصيلي.

التركيب الجزيئي للحمض النووي وقد تم تناوله بشكل تفصيلي.

• كما تضمن المحتوى مؤشرًا واحداً فقط من معيار الطب الجزيئي وهو:

التقنيات الأساسية للعلاج الجيني، وقد تم تناوله بثكل مختصر ، حيث ورد بأنه يتخيل بعض العلماء أنه قد يأتي الوقت الذي يمكن فيه إدخال نسخ من جينات

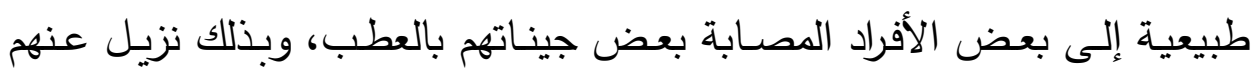

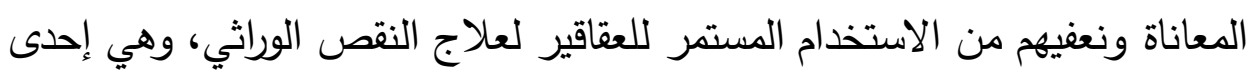

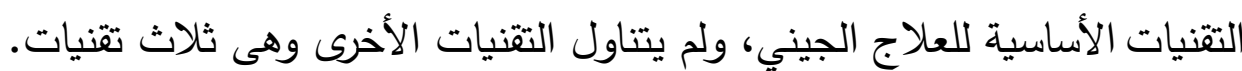

• كما تضمن المحتوى ثلاثة مؤشرات من معيار التطور والطفرات وهي: تعريف الطفرة الوراثية وقد تم تناوله بثكل تفصيلي. أنواع الطفرات الوراثية، وقد تم تناوله بشكل تفصيلي. أسباب حدوث الطفرة الوراثية، وقد تم تناوله بدرجة متوسطة، حيث ورد أنه قد يرجع

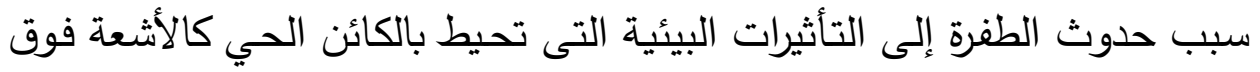


البنفيجية والأشعة الكونية، وأيضاً بسبب تعرض الكائن الحي للمركبات الكيميائية المختلفة ولم يتناول السبب الثالث لحدوث الطفرات.

كما تضمن المحتوى مؤشرًا واحداً فقط من معيار الزراعة والثروة الحيوانية وهو: أمثلة لبعض المحاصيل المقاومـة للأمـراض والجفاف والحشـرات، وقد تم تناولـهـ بثكل مختصر جداً؛ حيث ورد أنه قد يتكن الباحثون الزراعيون من إدخال جينات

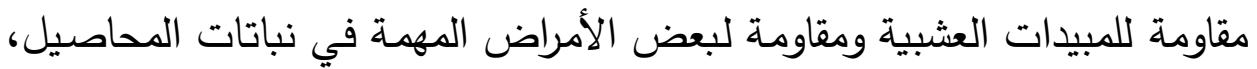
ولم يتتاول أمثلة لبعض المحاصيل المقاومة للأمراض والجفاف والحشرات. كما تضمن المحتوى مؤشرًا واحداً فقط من معيار الدراسات المقارنة وهو: أمثلة توضـح تحليل ومقارنـة المـادة الجينيـة وجينومـات الأنواع المختلفـة لدراسـة التطور، وقد تم تناوله بشكل مختصر ؛ حيث ورد أنه يتم دراسة تطور الكائنات

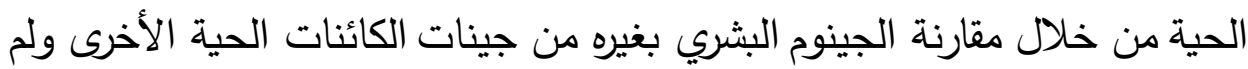
يتناول أي أمثلة توضح ذلك. كما تضمن المحتوى مؤشرًا واحداً فقط من معيار الحرب البيولوجية وهو: طرق الحرب البيولوجية وقد تم تتاوله بشكل مختصر، حيث ورد أنه لو فرضنا أن هناك سلالة بكتيرية بها جين لإنتاج مادة سامة خطرة قد تم إطلاقها في العالم ماذا سيحدث؟ وهذا يعتبر مثالا لإحدى الطريقتين اللتين تتم بهما الحرب البيولوجية. كما تضمن المحتوى مؤشرين من مؤشرات معيار التكنولوجيا الحيوية وهما: بعض تطبيقات الهندسة الوراثية، وقد تم تناوله بدرجة متوسطة، حيث ورد أنه قد

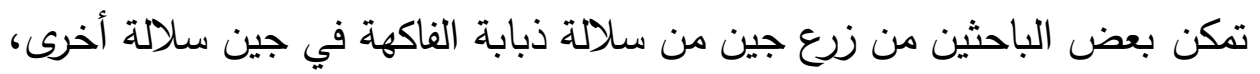

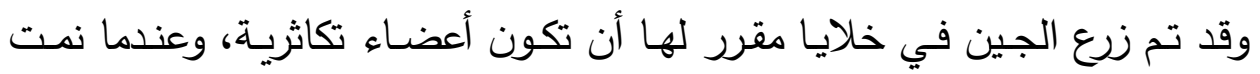

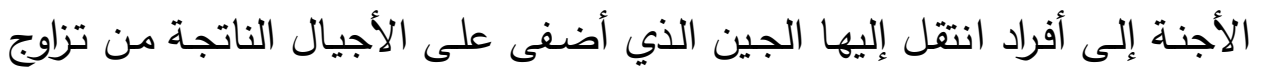

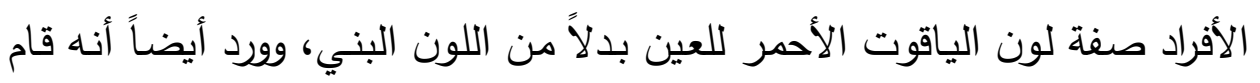

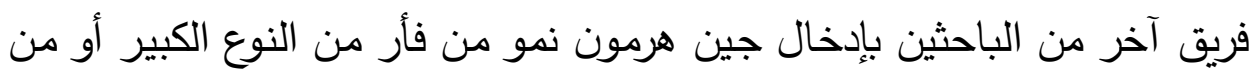

\section{$\varepsilon \pi$}


الإنسان إلى فئران من النوع الصغير ، حيث نمت هذه الفئران إلى ضعف حجمها

$$
\text { الطبيعي، ولم يتطرق لبعض التطبيقات الأخرى. }
$$

أمثلة لبعض الأمصال التى تم إنتاجها لأشخاص مصابين بالأمراض، قد تم تناوله

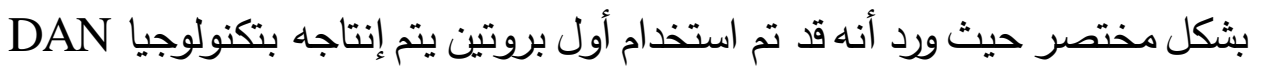

معاد الاتحاد،وهو هرمون الإنسولين البشري، ولم يتناول العديد من الأمثلة الأخرى.

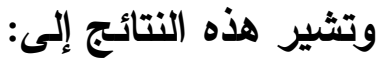

تدني مستوى تناول أهداف منهج الأحياء بالصفوف الثلاثة لمعايير ومؤشرات أهداف المعلوماتية الحيوية.

تدني مستوى تناول محتوى منهج الأحياء بالصفوف الثلاثة لمعايير ومؤشرات محتوى

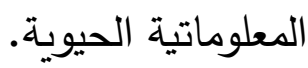




\section{المسـراجـع}

\section{أولًا : المــراجـع العـربيــة}

أبو زيد، أمساني محمد عبد الحميد (10 + ب). برنـامج لاعداد معلمي البيولوجيا في ضـوء المتغيرات البيومعلوماتية والبيو أخلاقية في عصر الجينوم البشرى. رسالة دكتوراة غير منشورة، كلية التربية: جامعة عين شس.

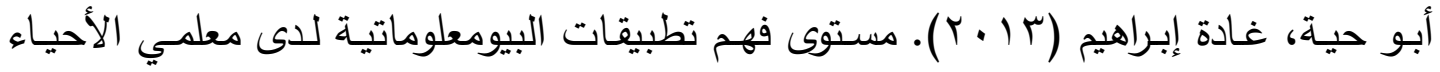
بالمرحلة الثانوية واتجاهاتهم نحوها. رسالة ماجستير غير منشورة، كلية التربية: الجامعة

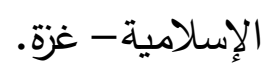

خبراء مركز تطوير المناهج والمواد التعليمية (r ـ ب). الإطار العام لمناهج المرحلة الثانوية. القاهرة: مركز تطوير المناهج والمواد التعليمية، وزارة التربية والتعليم، مصر . السيد، فؤاد البهي (ع ( ـ ب). علم النفس الإحصائي وقياس العقل البثري. القاهرة: دار الفكر العربي. طعيمة، رشدي أحمد (؟ . . ب). تحليل المحتوى في العلوم الإنسانية. القاهر: دار الفكر العربي. عرفات، نجاح المرسي السعدي ( ( ). دراسة تقويمية لمناهج الأحياء بالمرحلة الثانوية في ضوء

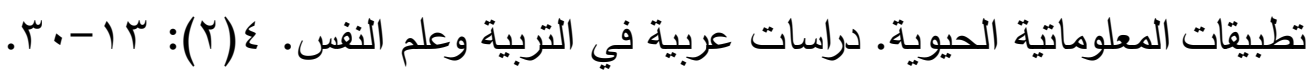

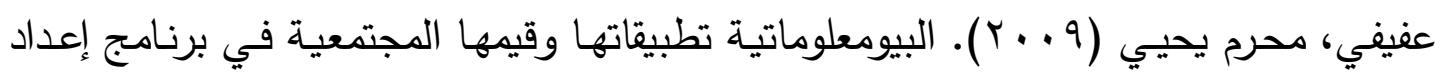
معلمي البيولوجي (دراسة تثخيصية- علاجية). المؤتمر العلمي الثالث عشر ، "التربية العلمية: المعلم، والمنهج، والكتاب دعوة للمراجعة" الجمعية المصرية للتربية العلمية،

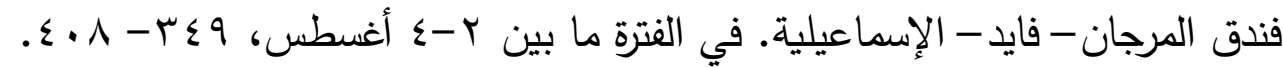

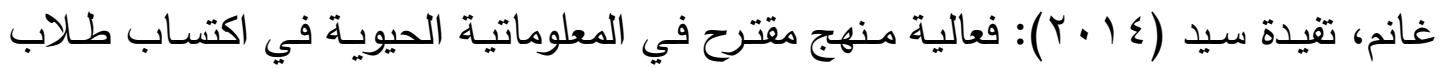
المرحلـة الثانويـة العامـة بعض مستويات التميز في الأحياء. مجلـة التربيـة العلميـة،

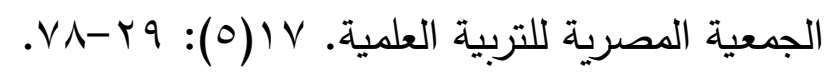




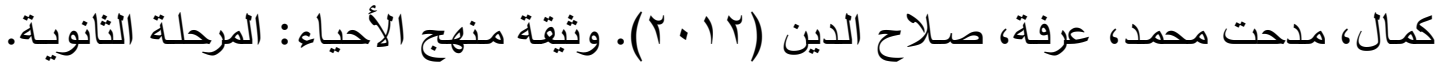
القاهرة: مركز تطوير المناهج والمواد التعليمية، وزارة التربية والتعليم، مصر .

المفتي، محمد أمين (ع 919 ). سلوك التدريس: سلسلة معالم تربوية. القاهرة: مركز الكتاب. الهراس، حسن السيد ودويدار ، أمين عرفان وفرج، عدلى كامل وإبراهيم، عبد الله محمد وكامل،

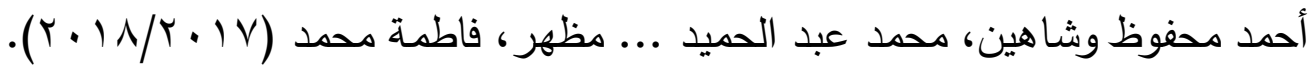
علم الأحياء للصف الثالث الثانوي. جمهورية مصر العربية: وزارة التربية والتعليم. وزارة التربية والتعليم (ץ. . ץ). المعايير القومية للتعليم في مصر ، وثيقة المستويات المعيارية

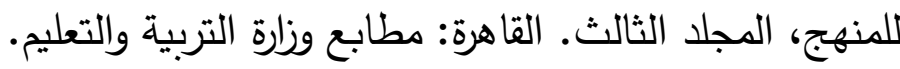

\section{ثانيا: الــــراجــع الأجنبيـــة}

Bednarski, A. E., Elgin, SC.R. \& Pakrasi, H B. (2005). An Inquiry into Protein Structure and Genetic Disease: Introducing Undergraduates to Bioinformatics in a Large Introductory Course. Cell Biology Education, 4, 207-220.

Bianchi, L \& Lio, P (2007). Forensic DNA and bioinformatics. Briefings in Bioinformatics , 8(2), 117-128.

Furge, L. L., Truss, R S., Moore, D B. \& Langeland, J. A. (2009). Vertical and Horizontal Integration of Bioinformatics Education. The International Union of Biochemistry and Molecular Biology, 27(1), 26-36.

Fulekar, M. H. (2009). Bioinformatics in Life and Enviromental Sciences. New Delhi, India: Capital Publishing Company.

Gallagher, S. R.; Coon, W.; Donley, K.; Scott, A. \& Goldberg, D. S, (2011). a First Attempt to Bring Computational Biology into Advanced High School Biology Classrooms .PLoS Computational Biology, 7(10) e1002244, 1-7. 
Gelbart, H. \& Yarden, A. (2006). Learning Genetics Through an authentic Research Simulation in Bioinformatics. Journal of Biological Education, 40(3), 107-112

Grisham,W., Schottler, N. A., Valli-Marill, J., Beck, L. \& Beatt, J. (2010). Teaching Bioinformatics and Neuroinformatics by Using Free Webbased Tools. CBE—Life Sciences Education, 9, 98- 107.

Howard, D. R. Miskowski, J. A. Grunwald, S K. \& Abler, M. L. (2007). Assessment of a Bioinformatics across Life Science Curricula Initiative. The International Union of Biochemistry and Molecular Biology, 35(1), 16-23.

Indra, N. S. (2010). Bioinformatics Education in the 21st Century. Briefings in Bioinformatics, 11(6), 535-536.

Kovarik, D. N., Patterson, D.G., Cohen, C., Sanders, E. A., Peterson, K. A., Porter, S.G., ... Chowning, J.T. (2013). Bioinformatics Education in High School: Implications for Promoting Science, Technology, Engineering, and Mathematics Careers. CBE-Life Sciences Education, 12, 441-459

Krishna, G. (2017). Brief Review on Bioinformatics. Biochemistry \& Molecular Biology Letters, 3(2), 1-8.

Kumar, A. \& Chordia, N. (2017). Role of Bioinformatics in Biotechnology. Research \& Reviews in BioSciences, 12(1), 1-6.

Lewitter, F. \& Bourne, P. E. (2011). Teaching Bioinformatics at the Secondary School Level. PLoS Computational Biology, 7(10) e1002242, 1-2. 
Littlejohn, T. (2001). Bioinformatics Tools for Genome Projects. in Developments in Plant Breeding: Molecular Breeding of Forage Crops, Edited by Spangenberg, G. 83-99. Springers Science + Business Media Dordrecht: Kluwer Academic Publishers.

Li, Y., Bai, Q. \& Chen, Z. (2014). Applications Domain Driven Data Mining Methodology in Bioinformatics. Biotechnology: an Indian Journal, 10(9), 3732-3739.

Luscombe, N. M., Greenbaum, D. \& Gerstein, M. (2001). What is Bioinformatics? A Proposed Definition and Overview of the Field. Method Inform Med, 4, 346-358.

Machluf, Y., Gelbart, H., Ben-Dor, S. \& Yarden, A. (2016). Making authentic science accessible - the benefits and challenges of integrating bioinformatics into a high-school science curriculum. Briefings in Bioinformatics, 22, 1-15.

Machluf, Y. \& Yarden, A. (2013). Integrating Bioinformatics into Senior

High School: Design Principles and Implications. Briefings in Bioinformatics, 14(5), 648-660.

Marcus, F. B. (2008). Bioinformatics and Systems Biology: Collaborative Research and Resources. Heidelberg, Germany: Springer- Verlag Berlin Heidelberg.

Marques, I., Almeida, P., Alves, R., Dias, M. J., Godinho, \& PereiraLeal, J. B. (2014). Bioinformatics Projects Supporting LifeSciences Learning in High Schools. PLoS Computational Biology, 10(1) e1003404, $1-6$. 
Priyadarshi, M. B. (2014). Applications of Bioinformatics. Biotech Articles. Retrieved from: http://www.biotecharticles.com/Bioinformatics Article/Applications-of-Bioinformatics-3270.html

Ramlo, S. E., McConnell, D., Duan, Z. H. \& Moore, F. B. (2008). Evaluating an Inquiry-Based Bioinformatics Course Using Q Methodology. Journal of Science Education and Technology, 17, 219-225.

Rao, V. S., Das, S. K., Rao, V. J. \& Srinubabum, G. (2008). Recent Developments in Life Sciences Research: Role of Bioinformatics. African Journal of Biotechnology, 7(5), 495-503.

Raza, K. (2010). Appliction of Data Mining in Bioinformatics. Indian Journal of Computer Science and Engineering, 1(2), 114-118.

Traynor, P. L., Frederick, R. \& Koch, M. (2002). Biosafety and Risk Assessment in Agricultural Biotechnology. Michigan State University, Board of Trustees: USA.

Wefer, S. H. \& Sheppard, K. (2008). Bioinformatics in High School Biology Curricula: A Study of State Science Standards. CBELife Sciences Education, 7, 155-162.

Weston, L. \& Hood, A. (2004). Systems Biology, Proteomics, and the Future of Health Care: Toward Predictive, Preventative, and Personalized Medicine. Journal of Proteome Research, 3, 179-196.

Xiong, J. (2006). Essential Bioinformatics. New York: Cambridge University Press. 
Zhang, X. (2009). Using Arabidopsis Genetic Sequences to Teach Bioinformatics. The International Union of Biochemistry and Molecular Biology, 37(1), 16-23.

\section{ثالثًا : المواقع التي تناولت الإتجاهات العاليـة لتضـهين المعلوماتيـة الحيويـة في المناهج الدراسية بالمرحلة الثانوية:}

Bioinformatics at Schools, Portugal . Retrieved March 25, 2017 from: http://en.bioinformatica-na-escola.org/.

Bioinformatics@School, Netherlands. Retrieved May 12, 2017 from: http://www3.cmbi.umcn.nl/bioidklas/en/. 